\title{
An analysis of the structure of an $n$-dodecane spray flame using TPDF modelling
}

\author{
Yuanjiang Pei ${ }^{\mathrm{a}}$, Evatt R. Hawkes ${ }^{\mathrm{b}, \mathrm{c}, *}$, Michele Bollac ${ }^{\mathrm{c}}$, Sanghoon Kook ${ }^{\mathrm{c}}$, \\ Graham M. Goldin ${ }^{\mathrm{d}}$, Yue Yang ${ }^{\mathrm{e}}$, Stephen B. Pope ${ }^{\mathrm{f}}$, Sibendu Som ${ }^{\mathrm{a}}$ \\ ${ }^{a}$ Transportation Technology Research and Development Center \\ Argonne National Laboratory, Argonne, IL 60439, USA \\ ${ }^{b}$ School of Photovoltaic and Renewable Energy Engineering \\ The University of New South Wales, Sydney, NSW 2052, Australia \\ ${ }^{c}$ School of Mechanical and Manufacturing Engineering \\ The University of New South Wales, Sydney, NSW 2052, Australia \\ ${ }^{d}$ Ansys Inc., Lebanon, New Hampshire, USA \\ e State Key Laboratory for Turbulence and Complex Systems \\ College of Engineering, Peking University, Beijing 100871, China \\ ${ }^{f}$ Sibley School of Mechanical and Aerospace Engineering \\ Cornell University, Ithaca, NY 14853, USA
}

\begin{abstract}
With a view to understanding ignition and combustion behaviours in diesel engines, this study investigates several aspects of ignition and combustion of an $n$-dodecane spray in a high pressure, high temperature chamber, known as Spray A, using data resulting from modelling using the transported probability density function (TPDF) method. The model has been validated comprehensively with good to excellent agreement in our previous work against all available experimental data including for mixture-fraction and velocity fields in non-reacting cases, and flame lift-off length and ignition delay in reacting cases. This good agreement encourages further investigation of the numeri-
\end{abstract}

\footnotetext{
*Corresponding author

Email address: evatt.hawkes@unsw.edu.au (Evatt R. Hawkes)
} 
cal model results to help understand the structure of this flame, which serves to complement the very limited experimental information that is available due to the difficult experimental conditions in which this flame exists. For example, quantitative experimental measurements of local mixture-fraction, temperature, velocity gradients, etc. are not possible in reacting cases. Analysis of the model results shows that two-stage ignition is found to occur across the ambient temperature conditions considered: the first stage is rapidly initiated on the lean side where temperatures are high and sequentially moves to richer, cooler conditions. The first stage is extremely resilient to turbulence, occurring in a region of very low Damköhler number. The second stage of ignition occurs first in rich mixtures in a region behind the head of the fuel jet where mixture gradients are low, and appears to be influenced strongly by turbulence. Relative to a homogeneous reactor, it is delayed on the lean side but advanced on the rich side, suggesting entrainment and mixing from the early igniting lean regions into richer mixtures is an important moderator of the ignition process. The second-stage ignition front propagates at very high velocities initially, suggesting it is a sequential ignition moving according to gradients of ignition delay and/or residence time. The flame stabilises however on the lean side in a region of much lower velocity, where turbulent velocity fluctuations are sufficiently high such that turbulent transport influences the propagation. It stabilises in a region of low Damköhler number which implies that a competition of chemistry versus micro-mixing might also be involved in stabilisation. The stabilisation mechanism is investigated by an analysis of the transport budgets, showing the flame is stabilised by autoignition but moderated by turbulent diffusion. Further analysis of the 
flame index supports this stabilisation mechanism, and demonstrates the simultaneous existence of non-premixed and premixed combustion modes in the same flame. Analysis of the flow fields also reveals that local entrainment and dilatation are important flow features near the flame base.

Keywords:

Spray A; Engine Combustion Network; Transported probability density function; Diesel; $n$-Dodecane 


\section{Introduction}

In the last two decades, significant progress has been made in using experimental techniques to understand the structure of diesel spray flames [1-7]. For example, in John E. Dec's landmark paper [2], imaging techniques employing Mie scattering, Rayleigh scattering, chemiluminescence, polycyclic aromatic hydrocarbon (PAH) fluorescence, and laser-induced incandescence were applied to develop a conceptual model of the structure of a diesel spray flame that was remarkably different to the physical pictures that were proposed before these techniques were available.

Many other works have followed and built upon this body of knowledge, e.g. see Ref. [7] for a review. For example, spray flames in a constantvolume combustion chamber under typical diesel engine conditions have been investigated in a forum known as the Engine Combustion Network (ECN) [8]. In particular, an $n$-dodecane spray flame, named Spray A has been a principal focus. Different facilities around the world have conducted experiments on Spray A conditions with different techniques to further understand spray flames under diesel engine conditions [9-14]. For example, in a constantvolume combustion vessel, Pickett et al. [10] investigated the relationship between vapor penetration and local fuel mixture fraction. Benajes et al. [11] characterized the ignition and lift-off length for Spray A in a constantpressure flow rig. Pickett et al. [9] and Meijer et al. [14] reviewed the Spray A experiments in different high-temperature and high-pressure facilities in the ECN community. Some computational studies to investigate Spray A have also recently been reported [15-27], for example, using RANS-based transported probability density function (TPDF) method $[15,23,26]$ and 
flamelet-type models [16-18] to demonstrate the importance of the effect of turbulence-chemistry-interaction (TCI) at diesel-engine conditions, and using large eddy simulation (LES)-type models [19-22, 24, 25] to demonstrate the capability of LES of simulating diesel spray.

Despite this substantial progress, the most detailed available experiments can still only provide a partial set of data - for example only one or two species would be simultaneously available, and these measurements are not quantitative. This stands in significant contrast to the situation with atmospheric pressure laboratory flames, where advanced experiments have been able to measure a large array of variables for some time: for example single point simultaneous measurements of all major species, some minor species, and temperature have been available for decades, e.g. [28-31], and more recently time- and space- resolved simultaneous measurements of some species and/or velocity and velocity gradients have become possible [32-34], with even some three-dimensional measurements also being reported $[35,36]$. Since such quantitative detail is not yet available in diesel engine conditions, much less is known about the details of ignition and combustion under these conditions than is known about these phenomena under atmospheric conditions.

In contrast, advanced models of turbulent combustion compute an approximation to the missing information, and therefore, once validated, can arguably suggest a qualitative picture of the missing data and infer characteristics of the flame structure which cannot yet be measured. Other studies have used model results in this way. For example, Gordon et al. [37, 38] simulated lifted laboratory flames using the TPDF method and investigated the flame stabilisation mechanism for different coflow temperatures. Ameen 
and Abraham [39] studied an n-heptane gas jet using flamelet progress variable (FPV) model and examined the fundamental physics affecting the lift-off length. Irannejad et al. [40] modelled an n-heptane spray and studied the ignition behavior for different ambient conditions using TPDF method. Jangi et al. [19] simulated Spray A and also investigated the flame stabilisation behavior using transport budgets analysis.

The goal of this paper is therefore to examine results from simulations of Spray A using a relatively complete model of turbulent combustion, the TPDF method, and infer some important characteristics of the flame structure associated with the two-stage ignition process and stabilisation mechanism. Specifically the objectives are to understand the effects of turbulence, mixing, and chemistry on the process of ignition, the transition to a stabilised flame, the mechanism of flame stabilisation, and the structure of the stabilised flame in terms of the combustion mode (premixed, non-premixed, etc.), turbulence parameters, forms of scalar PDFs, and the dimensionality of the thermochemical state-space.

The paper is organised as follows. The experimental and simulation details are briefly described in section 2, which also includes a brief summary of earlier validation of the modelling results against experimental data. The results are analysed according to the objectives outlined above in section 3 and finally a summary and discussion are reported in section 4 . 


\section{Methodology}

\subsection{Experimental setup}

The spray combustion experiments have been performed under the framework of the Engine Combustion Network [8]. In the present work, modelling results are validated against data from a constant volume preburn combustion vessel operated at Sandia National Laboratories $[9,10]$. The experiments considered fuel injection into a high pressure and high temperature ambient environment. This environment is achieved through igniting a pre-filled diluted mixture, then cooling for a relatively long period (seconds) to reach the target ambient conditions. Liquid fuel is injected into the nominally quiescent ambient environment, evaporates, ignites and eventually there is a transition to a quasi-stationary flame that is lifted from the nozzle. Key experimental details are listed in Table. 1.

Three cases that having different initial temperatures are considered in this study for numerical investigations, as shown in Table 2.

\subsection{Model and numerical parameters}

The modelling methods used are outlined extensively in previous work $[26,27,41,42]$, so only a brief account is repeated here.

TPDF model. The composition TPDF model is implemented in the commercial code Fluent [43] using a Lagrangian Monte Carlo approach. The conventional hybrid Eulerian-Lagrangian method is adopted, where the flow is modelled with a Reynolds-Averaged Navier-Stokes (RANS) based $k-\epsilon$ turbulence model. The unclosed turbulent flux term is modelled using the 
Table 1: Experimental boundary conditions

\begin{tabular}{ll}
\hline Fuel & n-dodecane \\
Fuel density $\left(\mathrm{kg} / \mathrm{m}^{3}\right)$ & 698 \\
Fuel temperature $(\mathrm{K})$ & 363 \\
Nominal nozzle-hole diameter $(\mathrm{mm})$ & 0.09 \\
Common-rail pressure $(\mathrm{MPa})$ & 150 \\
Injection velocity $(\mathrm{m} / \mathrm{s})$ & $595^{a}$ \\
Ambient density $\left(\mathrm{kg} / \mathrm{m}^{3}\right)$ & 22.8 \\
Ambient mixture composition $(\%)^{b}$ & $\mathrm{O}_{2}(15)$ \\
& $\mathrm{N}_{2}(75.15)$ \\
& $\mathrm{CO}_{2}(6.22)$ \\
& $\mathrm{H}_{2} \mathrm{O}(3.62)$ \\
\hline
\end{tabular}

a Not measured. Computed using nozzle discharge coefficient.

b Mole fraction.

assumption of gradient diffusion, which is implemented by incrementing particle positions using a Wiener process. The Euclidean Minimum Spanning Tree (EMST) mixing model is used [44] with a mixing constant $\mathrm{C}_{\phi}$ equal to 1.5 to close the micro-mixing term. A fractional step method is adopted to treat the convection, and mixing and reaction to facilitate the implementation [45].

Chemistry mechanism. The 88 species reduced chemical mechanism introduced in Ref. [26] was employed. It was based on a detailed mechanism from LLNL consisting of 2885 species and 11754 reactions [46], which has been val- 
Table 2: Investigated cases.

\begin{tabular}{lll}
\hline $\mathrm{T}_{a m b}(K)$ & $O_{2}(\%)$ & $P_{a m b}(\mathrm{MPa})$ \\
\hline 800 & 15 & 5.25 \\
900 & 15 & 5.94 \\
1100 & 15 & 7.30 \\
\hline
\end{tabular}

idated over a wide range of conditions and data-sets. This large mechanism was first reduced to a skeletal mechanism containing 106 species as described in Luo et al. [47], which was extensively validated against the detailed mechanism and experiments in a number of configurations including autoignition, jet stirred reactors (JSR), laminar premixed flames and counter flow diffusion flames. To this skeletal mechanism an $\mathrm{OH}^{*}$ sub-mechanism [48] was added in order to facilitate comparison with experimental chemiluminescence images. Quasi-steady state approximations were then applied very conservatively, and the final mechanism was revalidated in wide-ranging conditions. The final mechanism has been used as one of the benchmark mechanisms for the ECN workshop 3 by several research groups [8]. The reduced mechanism is believed to be able to capture the main ignition and combustion characteristics of the experiments, for example, the structure of $\mathrm{OH}^{*}$ fields was reasonably predicted by this reduced mechanism compared with measurements [26].

In-situ adaptive tabulation (ISAT) [49] was also used to accelerate the chemistry. A previous study has suggested that the use of ISAT does not change the solution, e.g., the onset of auto-ignition, in this transient diesel spray flame [41], and therefore will not affect the numerical analysis in this 
study.

Spray model. Spray was modelled with a fairly standard Lagrangian discrete phase approach [50], with a simple approach to coupling. Parcels of droplets were injected with defined velocity and diameter, and were subjected to drag according to a high Mach number law [51]. A stochastic approach [52] was used to treat the turbulent dispersion. The Frossling model [53] and the Ranz-Marshall approach [54] were used for evaporation and heat transfer, respectively.

Turbulence model and numerical parameters. A pressure-based transient solver was coupled with the standard Reynolds-averaged $k-\epsilon$ turbulence model. The discretisation scheme of SIMPLE for pressure-velocity coupling [55] and Rhie-Chow [56] interpolation for pressure were employed for the simulation. A first order upwind discretisation of convective terms was used. The radiation effect is not considered in this study. A detailed description of the methods employed is provided in the Fluent manual [43].

The modelling used a two-dimensional axisymmetric grid that has dimensions of 100 by $63 \mathrm{~mm}$, with a total cell number of 2385 . The minimum grid size is $0.25 \mathrm{~mm}$ and gradually stretched towards axial and radial directions. The mesh details can be found in Ref. [41]. A time-step of $4 \mu \mathrm{s}, 200 \mathrm{PDF}$ particles per cell and an ISAT error tolerance value of $10^{-5}$ were used. Extensive convergence tests were performed to ensure the adequacy of these parameters - these are reported in Refs. [26, 41].

Validation. Our previous study [26] validated the model extensively against all experimental data that were available for this flame. For non-reacting 
cases, the validation included, for a range of different conditions of ambient density, ambient temperature and injection pressure: liquid and fuel vapour penetration, profiles of the mean and variance of mixture-fraction, and profiles of mean velocity. For reacting cases, the validation included ignition delay and lift-off lengths as ambient temperature, ambient oxygen, ambient density, and fuel injection pressure were varied. The agreement was generally very good and for many quantities excellent. For example, Fig. 1 shows the experimental and computed lift-off length as the ambient temperature in the vessel is varied. The agreement is observed to be quantitatively excellent. The results are among the best of all attempts to model this flame to date [57], which encourages further investigation of the modelled results.

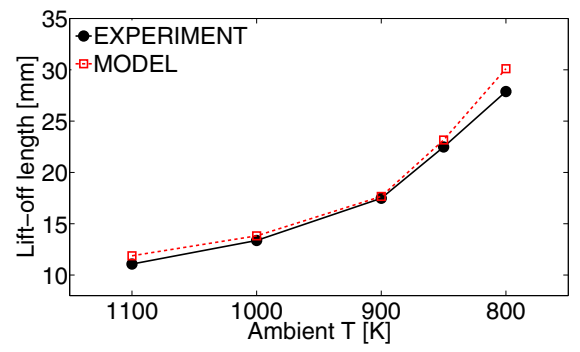

Figure 1: Experimental and modelled lift-off length at different ambient temperature conditions. Data points are repeated from Ref. [26].

\section{Results and discussion}

\subsection{Ignition}

Figure 2 presents a scatter plot of temperature versus mixture fraction for a sequence of times, and the three different temperatures. The sequence 


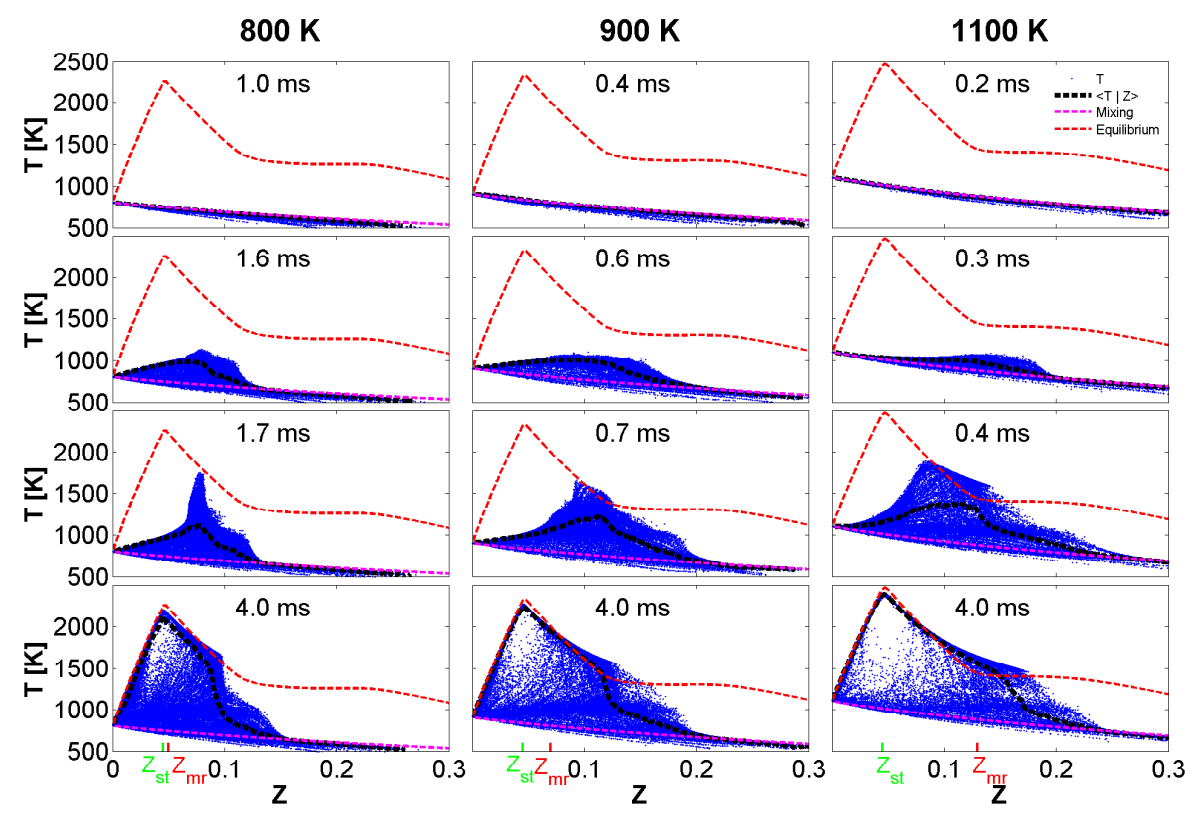

Figure 2: Temporal evolution of scatter plots of temperature versus mixture fraction at different ambient temperature conditions. The black dashed line is the mean temperature conditional on mixture fraction. The pink and red lines are mixing and equilibrium lines, respectively. 
of times has been chosen for each ambient temperature case to show a progression of ignition stages. At the early times in the first row, temperatures lie close to the mixing line, and ignition has not yet commenced. A two stage ignition is observed across all of the considered conditions, and the second row shows the temperatures after the first stage has progressed across a range of mixture fractions from very lean to much richer than stoichiometric (here the stoichiometric mixture fraction, $\mathrm{Z}_{s t}$ is 0.045 ). The third row shows the initial second stage ignitions, where temperatures for some particles are approaching equilibrium. These initial second stage ignitions occur rich of stoichiometric, and the location in mixture-fraction space is observed to increase with the ambient temperature. The Favre-averaged most-reactive mixture fraction, $\mathrm{Z}_{m r}$, defined here as the mixture having the shortest secondstage ignition delay if ignited in a constant pressure, homogeneous reactor [58], is also marked on the plots. This always occurs in mixtures richer than stoichiometric, but it is noted that the second stage ignition occurs at even richer mixtures than suggested by the most reactive mixture in a homogeneous reactor. The fourth row shows the scatter plots once a stable flame has been established. By this stage there are many particles close to the equilibrium line (as calculated by EQUIL [59]), particularly around stoichiometric. The high temperature region extends to very low mixture fractions and well beyond stoichiometric on the rich side, particularly at higher ambient temperature conditions. For all three cases, in mixture-fraction space, the high temperature region also extends to very low mixture fractions, corresponding to the spray boundary downstream of the lift-off location. On the fuel-rich side, the maximal mixture-fraction values are decreased with lower 
ambient temperatures and this is due to the increased fuel-air mixing upstream of the lift-off length because lower ambient temperatures have longer lift-off lengths (consistent with the finding reported in an n-heptane spray flame numerical analysis [40]). The super-equilibrium temperatures observed on the rich side are probably the result of mixing from leaner regions which have higher temperatures.

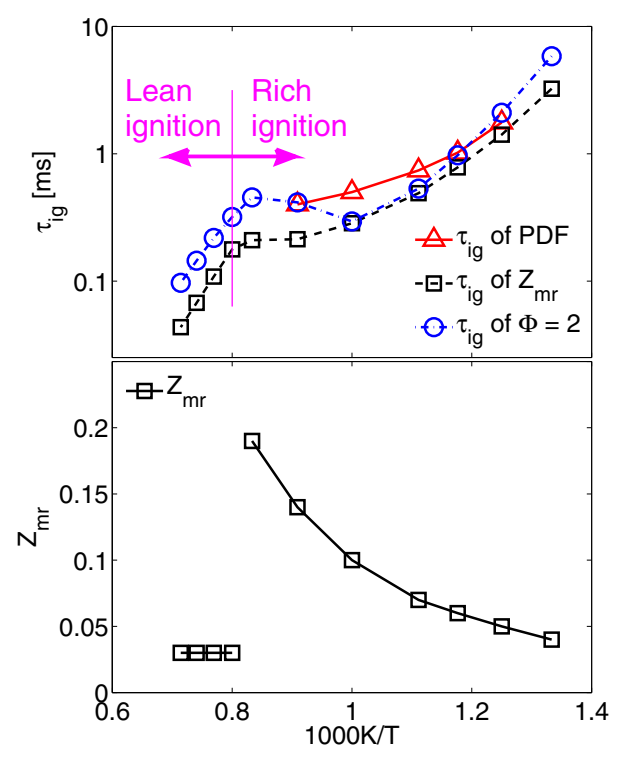

Figure 3: Comparison of ignition delay from the PDF model and $\mathrm{Z}_{m r}$ and a homogeneous reactor (HR) at different ambient $\mathrm{T}$. The corresponding $\mathrm{Z}_{m r}$ is shown in the bottom plot.

The progression of the ignition towards richer mixtures as ambient temperature was increased, as shown in Fig. 2, was not initially anticipated, and it turns out to be important to explain why a negative temperature coefficient (NTC) is not observed in the modelled or experimental ignition delays, as ambient temperature is varied. This is further investigated in Fig. 3, which 
on the top half, shows the ignition delay of the PDF model results, the most reactive mixture fraction in a homogeneous, constant pressure reactor, and the ignition delay of the $\phi=2$ mixture. On the bottom half, the most reactive mixture fraction is plotted for the homogeneous reactor. The PDF results are always longer than the homogeneous reactor results, but the trend is very similar. What is observed is that although the $\phi=2$ result has a clear NTC range, the ignition delay of the most reactive mixture fraction does not. What occurs is that as temperature is increased up to around $1250 \mathrm{~K}$, the ignition moves to progressively richer mixtures and the ignition delay continues to decrease. However, at the same time, as temperature is increased, the ignition delay of leaner mixtures also decreases, and eventually around $1250 \mathrm{~K}$ the ignition swaps over from a rich ignition to a lean ignition.

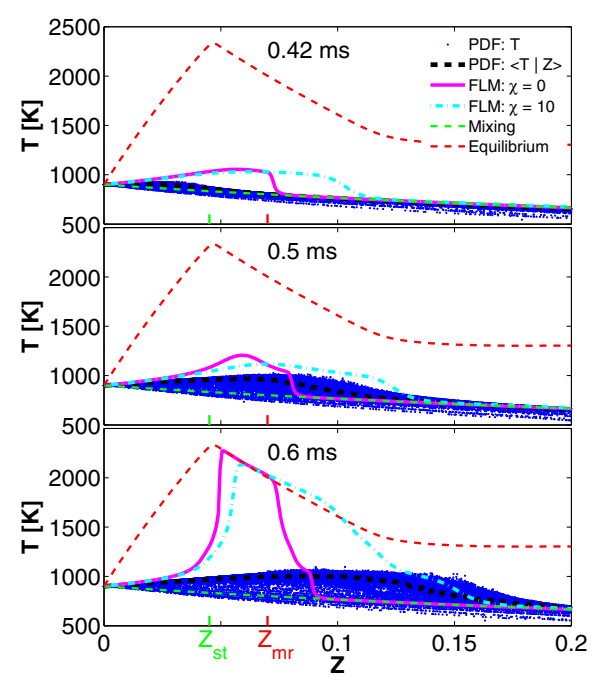

Figure 4: Particle temperatures versus mixture fraction, and results from a flamelet model with a specified scalar dissipation rate.

The first stage ignition is now examined more closely for the baseline 900 
$\mathrm{K}$ ambient temperature case in Fig. 4. The PDF results are compared with two sets of results from an unsteady flamelet model calculation, one with a peak scalar dissipation rate, $\chi$, of 0 and one with $10 \mathrm{~s}^{-1}$. In the case of zero dissipation rate, a flamelet solution [60] is simply a set of uncoupled homogeneous constant pressure reactors. Considering first the results at $0.42 \mathrm{~ms}$, it is clear that the first stage ignition is initiated very lean of stoichiometric but with minimal heat release. At this instant, the PDF model lags the $\chi=$ $0 \mathrm{~s}^{-1}$ flamelet model in terms of ignition progress. At $0.5 \mathrm{~ms}$ and $0.6 \mathrm{~ms}$, it is observed that for mixtures leaner than around a mixture fraction of 0.09 , the PDF model still lags the $\chi=0 \mathrm{~s}^{-1}$ flamelet model, which has entered second stage thermal runaway over a range of mixture fractions. However, in the region richer than around $\mathrm{Z}=0.09$, the $\mathrm{PDF}$ model actually leads the $\chi=0 \mathrm{~s}^{-1}$ flamelet model. Due to the finite time to form a flammable mixture and due to losses of heat and radicals from early igniting regions, this situation was not initially expected. It is postulated that this is a result of turbulent mixing: transport, by turbulence and/or by entrainment, of heat and radicals from early first stage ignition in leaner regions into richer regions accelerates the ignition in the latter. Comparing the $\chi=0 \mathrm{~s}^{-1}$ with $\chi=10 \mathrm{~s}^{-1}$ flamelet solutions, where mixing is included in the latter but not in the former, supports this explanation. This result is not without support in the literature - other numerical simulations of an igniting mixing layer demonstrated that mixing effects can enhance second stage ignition [61, 62]. This also partially explains why the second stage ignition in Fig. 2 (at 0.7 ms) was observed to occur in mixtures that were richer than what would be predicted by the most reactive homogeneous reactor. 


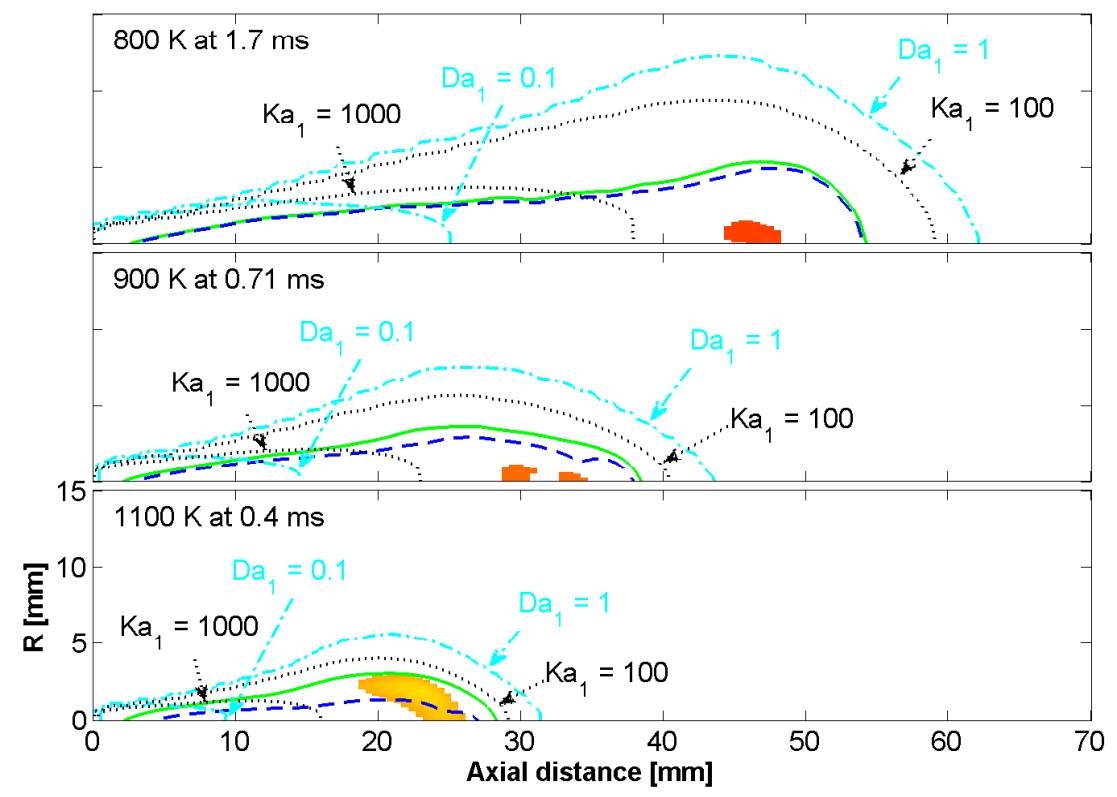

Figure 5: Ignition stations at different ambient temperature conditions. The green solid line is the contour of $\mathrm{Z}_{s t}$ and the blue dashed line is the contour of $\mathrm{Z}_{m r}$. The cyan dash-dot line represents the contour of Damköhler number and the black dotted line is the contour of Karlovitz number. The colour area represents the temperature of $400 \mathrm{~K}$ above the ambient temperature.

The spatial location of this initial second stage ignitions is now examined in Fig. 5 for the different ambient temperature conditions. The contours of the stoichiometric and most-reactive mixture fractions are shown and ignition is visualised by marking the area that has a mean temperature at least 400 $\mathrm{K}$ above ambient. In all cases, the ignition is observed to occur in a region rich of $\mathrm{Z}_{m r}$ just behind the head of the spray. It is also interesting to note that the ignition locations are approaching the $\mathrm{Z}_{m r}$ contours when increasing the ambient temperatures. The ignition still occurs in the region behind the 
head of the spray as temperature is increased, but this region coincides more with the regions close to those $\mathrm{Z}_{m r}$, since $\mathrm{Z}_{m r}$ moves towards richer mixtures.

To investigate the reasons for the ignition location to be where it is, contours of Karlovitz number, Ka, and Damköhler number, Da, are also shown in Fig. 5. Here, $\mathrm{Ka}_{1}$ and $\mathrm{Da}_{1}$ have been defined as:

$$
\mathrm{Ka}_{1}=\frac{\tau_{c, 1}}{\tau_{\eta}} \quad \text { and } \quad \mathrm{Da}_{1}=\frac{\tau_{t}}{\tau_{c, 1}}
$$

where $\tau_{c, 1}$ is the ignition delay of the most reactive mixture fraction in a homogeneous reactor, $\tau_{\eta}$ is the Kolmogorov timescale, and $\tau_{t}$ is the integral timescale. The figures for 800 and $900 \mathrm{~K}$ show that turbulence is relatively more intense (i.e. higher Ka and lower Da) in the ignition location compared with the theoretically more reactive conditions further downstream. Thus, for these temperatures, increased turbulent micro-mixing rates (represented by Ka and Da), which we assume will have the effect to retard ignition [6367 ], does not explain the location of the ignition. For the $1100 \mathrm{~K}$ case, the ignition does occur in a region of less intense turbulence, but the lack of consistency with the other two cases suggests this is not the reason for the observed ignition location.

Interestingly, however, it is observed that in all three temperatures, the ignition occurs in a region of relatively high $\mathrm{Ka}>100$ and low $\mathrm{Da}<1$. This implies significant turbulent mixing occurs during ignition.

This relatively rich second stage ignition is further examined in Fig. 6, which shows an axial profile of the mean mixture fraction and $\mathrm{OH}$ mass fraction on the centre-line for the different ambient temperature cases close to the time of ignition. It is readily observed that at the head of the jet, very steep gradients of mixture fraction exist, up to a critical mixture fraction 


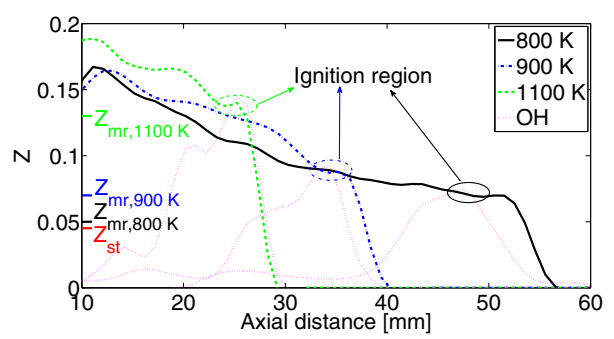

Figure 6: Mixture fraction and $\mathrm{OH}$ mass fraction (pink lines normalised by its maximum value) on the centreline at the time of ignition for different ambient temperature cases.

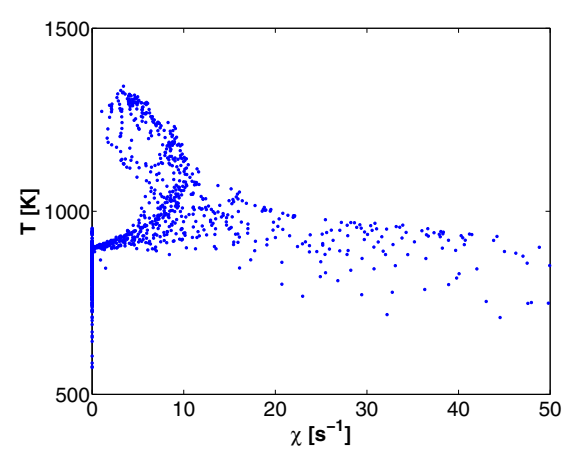

Figure 7: Scatter plot of temperature versus scalar dissipation rate at the time of ignition for the $900 \mathrm{~K}$ ambient temperature case.

of about 0.09 for the $900 \mathrm{~K}$ case, which is richer than the most reactive mixture fraction of 0.07 . Figure 7 presents the scatter plot of temperature in scalar dissipation rate space at the time of ignition for the $900 \mathrm{~K}$ ambient temperature condition. It is clearly seen that the high temperature region (where ignition happens) has the lower scalar dissipation rates. This also holds true for the other two ambient cases. The reason for the second stage ignition occurring preferentially in richer mixtures now becomes clear: the gradients in the leaner regions are large due to the straining effect at the head of the jet, while in richer mixtures the gradients are much lower. The 
gradients essentially control the turbulent transport between the ignition kernel and its surroundings, and as such ignition should be expected in a lower gradient region.

Summarising the findings with respect to the ignition location, it is found that second-stage ignition occurs faster than expected in rich mixtures because of mixing from the first-stage ignition products of leaner regions; these leaner regions, however, do not themselves go into second-stage ignition because gradients are too high, and both effects combined lead to ignition occurring in rich mixtures.

\subsection{Transition to a stabilised flame}

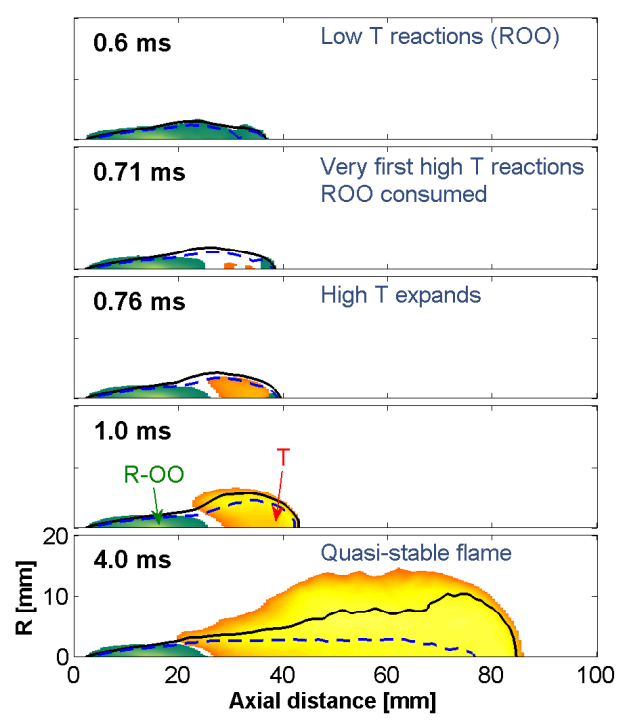

Figure 8: Time evolution of the flame from ignition to stabilisation at $900 \mathrm{~K}$ ambient temperature condition. The black solid line is the contour of $\mathrm{Z}_{s t}$ and the blue dashed line is the contour of $\mathrm{Z}_{m r}$.

The green flood in Fig. 8 shows contours of the Favre-averaged mass frac- 
tion of dodecyl peroxy radical (denoted here R-OO), a key intermediate in the low-temperature degenerated chain branching process that governs the first stage of ignition [68], while the yellow flood shows contours of Favre-averaged temperature cut-off at $1300 \mathrm{~K}$, thus representing the region of high temperature combustion. The Favre-averaged stoichiometric mixture fraction $\mathrm{Z}_{s t}$ contour is marked with a solid black line while the Favre-averaged mostreactive mixture fraction $\mathrm{Z}_{m r}$ contour is noted with a dashed blue line. It is observed that the low temperature kinetic pathways indicated by the high ROO region, which are active during first stage ignition, initiate rapidly across a range of mixture fractions. The second, hotter ignition begins behind the head of the fuel jet that is rich of stoichiometric, and then expands outwards, consuming the products of the first stage, and eventually stabilising on the lean side of stoichiometric. This picture is consistent with the high-speed shadowgraph movies of reacting jets reported in Refs. [11, 69, 70], which showed that the signal disappeared (became transparent to the background) just before the second-stage ignition. It also agrees with findings from two reacting jets at Spray A condition reported in Refs. [13, 71] that the consumption of formaldehyde measured by a pulsed 355-nm planar laser sheet coincides with the location and timing of the second-stage ignition measured by the schlieren imaging. Between $0.7 \mathrm{~ms}$ and $4.0 \mathrm{~ms}$, the high temperature region expands, corresponding to the so-called "premixed burn" phase of combustion [1]. Overall these features are also consistent with Dec's conceptual model [2] and the proposed adjustments (e.g., more premixing of fuel and air due to longer ignition delay, and more distinct and temporally extended two-stage ignition, etc.) for lower-temperature combustion condi- 
tions [7] (as the Spray A condition with 15\% oxygen represents a moderate dilution level).

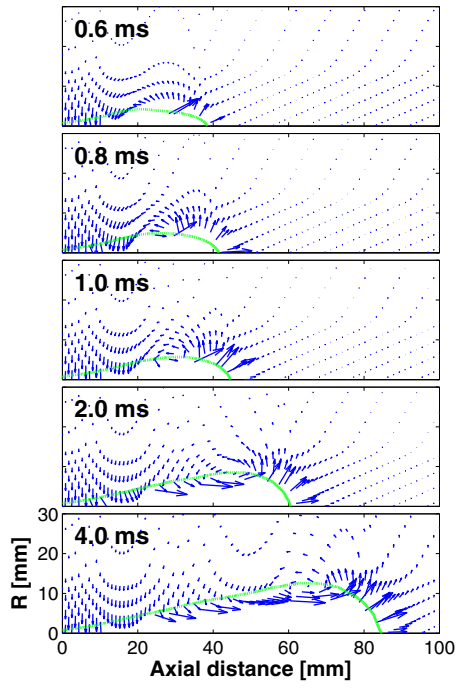

(a) Non-reacting case

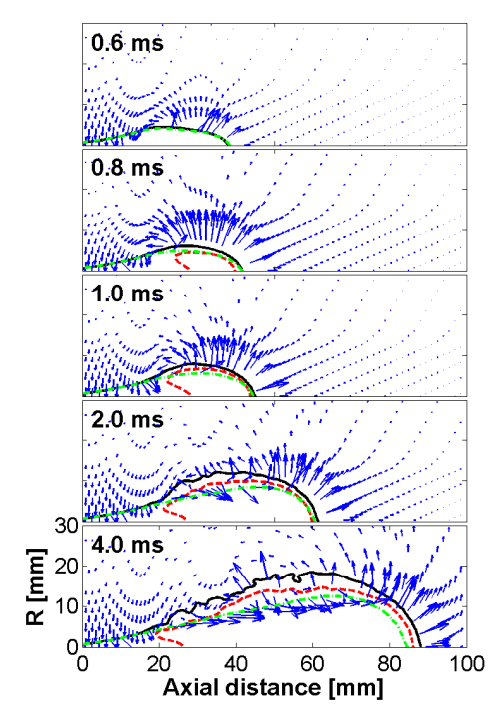

(b) Reacting case

Figure 9: Velocity vectors of the (a) non-reacting and (b) reacting cases at $900 \mathrm{~K}$ ambient temperature condition; black line: contour of $\mathrm{Z}=0.001$; green dashed line: contour of $\mathrm{Z}$ $=0.001$ of an equivalent non-reacting jet; red dashed line: $\mathrm{T}=1300 \mathrm{~K}$.

Dilitational effect. Flow effects are examined in more detail for a set of nonreacting (Fig. 9(a)) and reacting (Fig. 9(b)) cases at $900 \mathrm{~K}$ ambient temperature condition, which plots Favre-averaged velocity vectors in the periphery of the jet, the $1300 \mathrm{~K}$ contour of mean temperature demarking the flame region, the contour of the mixture fraction 0.001 of the reacting jet as a black line, and for reference the contour of the same value of mixture fraction in a corresponding non-reacting jet in an oxygen-free environment as a green 
dashed line. Considering first the non-reacting case in Fig. 9(a), the vectors show the expected features of a transient jet. Axial velocities peak on the centre line and there is a radially diverging flow around the jet head. Entrainment is evident towards the nozzle. Just behind the head of the jet, the combination of the radially diverging flow at the head and the entrainment flow behind creates a counter-clockwise vortex. This feature is also observed in experimental PIV measurements of the same case [72]. Turning to the reacting case in Fig. 9(b), some features of the flow are similar. However, the effect of dilatation due to combustion is significant. For example at 1.0 ms, there is a strong outwardly expanding flow around the region of high temperature, due to an intense premixed burn. Very interestingly, this couples with the entraining flow to create an even stronger counter clockwise vortex (as compared with the non-reacting case) which centres at the flame base. The vortex is strong enough to actually reverse the flow to the direction back towards the nozzle, which may lead to transport of hot products upstream of the flame base, thus accelerating ignition and promoting flame stabilisation further downstream. For the stabilised flame, the main vortex has moved further downstream, however, there is still certainly reversed flow in the vicinity of the flame base on the lean side, as shown in the zoom view in Fig. 10. Also interesting is that in the region where dilatation is significant, it appears to counteract entrainment such that the entrainment appears to be overall lower compared with the non-reacting case. This feature is also observed in PIV experiments [72].

Comparison of the reacting and non-reacting mixture fraction contours (0.001) confirms the dilatational effect, as the reacting contour clearly bulges 


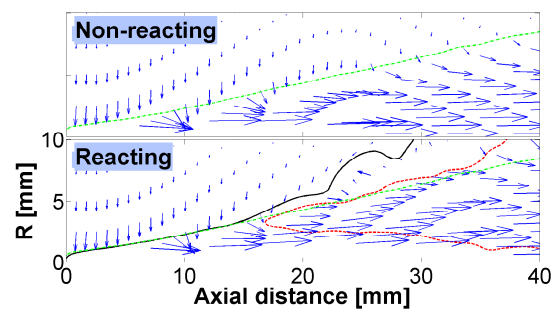

Figure 10: Zoom plots of velocity vectors at stabilisation stations at $\mathrm{T}_{a m b}=900 \mathrm{~K}$. The black solid line is the reacting boundary and green dash-dot line is the non-reacting boundary. The red dashed line is flame existing and the blue arrows are the ambient velocity vectors (logarithmic scale) with threshold $60 \mathrm{~m} / \mathrm{s}$.

out in the vicinity of the flame base. The findings are quite consistent with the picture presented in Pickett et al. [73] in which it is argued that a reservoir of high temperature products on the jet periphery supports the flame stabilisation.

\subsection{Stabilisation mechanism}

The stabilisation mechanism of the diesel flame has been a subject of considerable discussion, e.g. [73-76]. In particular there are questions as to whether turbulent transport of heat and radicals in the upstream direction could play any role [37]. Here, this question is probed by investigating the speed of the advancing flame. The position of the leading edge of the flame, defined as the first axial location which exceeded $400 \mathrm{~K}$ above the ambient temperature was extracted. The flow velocity was interpolated to this location so that a relative displacement speed of the combustion front could be determined. Figure 11 plots the obtained front speed versus time at $900 \mathrm{~K}$ ambient temperature condition. It is observed that the front speed is initially extremely high, order $200 \mathrm{~m} / \mathrm{s}$, which considerably exceeds plausible values 
of a turbulent premixed flame speed. In this transitional phase, therefore, the front is certainly a spontaneous ignition front propagating according to gradients of ignition delay and/or residence time [77-80]. However, the front stabilises in a region of much lower velocity, of the order of $10 \mathrm{~m} / \mathrm{s}$. As this is the same order of magnitude as the turbulent velocity fluctuation at this location, around $9 \mathrm{~m} / \mathrm{s}$, it suggests that turbulent transport could play a role in the stabilisation.

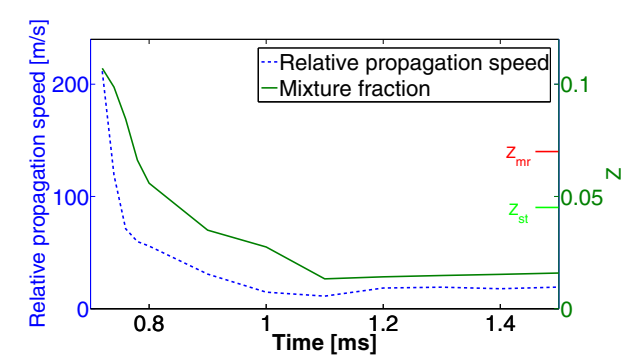

Figure 11: Relative axial propagation speed of the advancing flame front and the location of the front in mixture fraction space at the $900 \mathrm{~K}$ ambient temperature condition.

Also shown in Fig. 11 is the mixture fraction at the front location, showing that second stage ignition is initiated in mixtures that are considerably richer than expected without considering any mixing effects, but that it eventually transitions to a region that is actually leaner than stoichiometric - presumably because the opposing flow velocity there is much lower.

The mechanism of flame stabilisation is now investigated further following an analysis introduced by Gordon et al. [37]. Figure 12 shows terms in the implied transport equation of the Favre-averaged $\mathrm{OH}$ mass fraction, a marker of high-temperature combustion, at different ambient temperature conditions. The terms investigated are the implied mean reaction rate, convection, and 


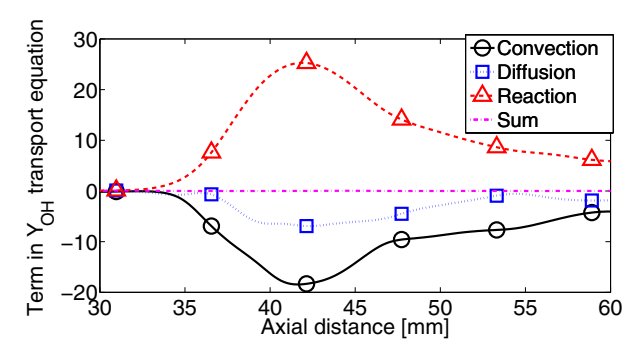

(a) $800 \mathrm{~K}$

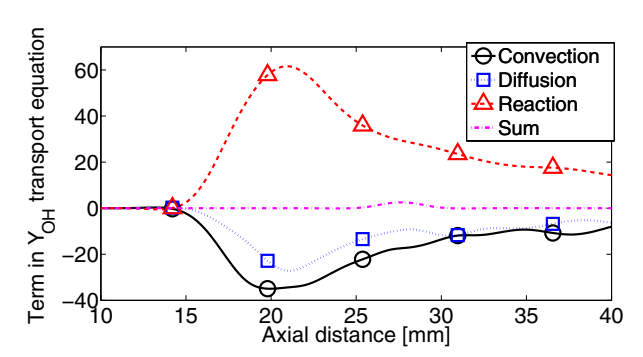

(b) $900 \mathrm{~K}$

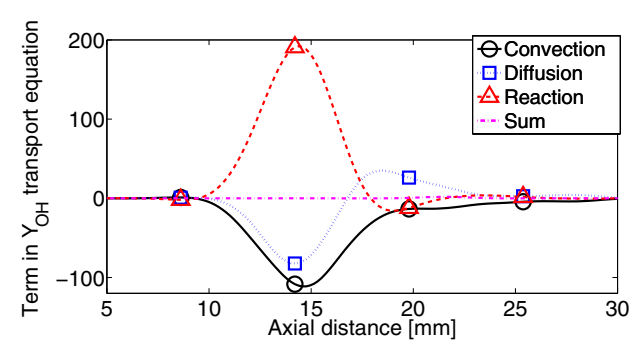

(c) $1100 \mathrm{~K}$

Figure 12: Streamwise convection, diffusion and reaction terms across the stabilisation location for (a) $800 \mathrm{~K}$, (b) $900 \mathrm{~K}$ and (c) $1100 \mathrm{~K}$ ambient temperature conditions.

turbulent diffusion. These were obtained directly from particle data by finding the time-averaged difference between the mean $\mathrm{Y}_{O H}$ field at different points in the TPDF fractional step algorithm. Figure 12 shows a streamwise profile through the flame at the radial position of stabilisation for the 
three ambient temperature conditions accordingly. Figure 12 clearly shows that all three terms are important: reaction is a large term that is balanced by convection and turbulent diffusion, which have comparable magnitude. Moreover, the importance of turbulent diffusion term becomes more significant with increased ambient temperature. Additional analysis of these terms suggested that the convection is dominated by streamwise convection with a small contribution from the entrainment flow, while turbulent diffusion is dominated by radial diffusion with virtually no contribution of streamwise turbulent transport. As discussed in Gordon et al. [37], streamwise turbulent transport is expected in a turbulent premixed flame. The results therefore suggest that the flame stabilisation is controlled by autoignition rather than by a premixed flame. However the stabilisation mechanism is not purely autoignitive: it is moderated by turbulent diffusion of heat and radicals out of the flame, which may go some way to explaining experimental observations of an unexpectedly slow downstream movement of the flame location after ignition by an upstream laser source [73].

\subsection{Flame index}

The flame index is a very useful tool to understand the flame structure and distinguish the diffusion and premixed flames to aid the analysis of the flame stabilisation mechanism [81]. The flame index (FI) is given by

$$
F I=\nabla \tilde{Y}_{f} \cdot \nabla \tilde{Y}_{o x}
$$

where $\widetilde{Y}_{f}$ and $\widetilde{Y}_{o x}$ are the Favre-averaged fuel and oxidiser mass fractions, respectively. To obtain the flame index shown in Fig. 13, fuel breaking down in the first ignition stage was taken into account by adding together all the 
mass fractions of products of the first stage ignition (e.g., $\mathrm{C}_{12} \mathrm{H}_{26}, \mathrm{CH}_{2} \mathrm{O}$, $\mathrm{CH}_{3} \mathrm{CHO}, \mathrm{C}_{8} \mathrm{H}_{17} \mathrm{COCH}_{2}$ etc.), which is taken as the "fuel" mass fraction in equation 2. The $\mathrm{O}_{2}$ mass fraction is used for the oxidiser mass fraction in the calculation. The flame index as reported in Fig. 13 exhibits a region upstream of and around the flame base, which is negative (i.e. a non-premixed orientation of fuel and oxidiser gradients), and approximately aligned with the stoichiometric contour. The flame is evidently stabilised in this region, once again suggesting an essentially non-premixed, autoignitive mode of stabilisation and supporting the earlier analysis of the flame stabilisation mechanism using the balance of convection, diffusion and reaction budgets. Just downstream of the flame base there is an indeterminate transitional region, and in the central, rich region the flame index is positive suggesting premixed burning.

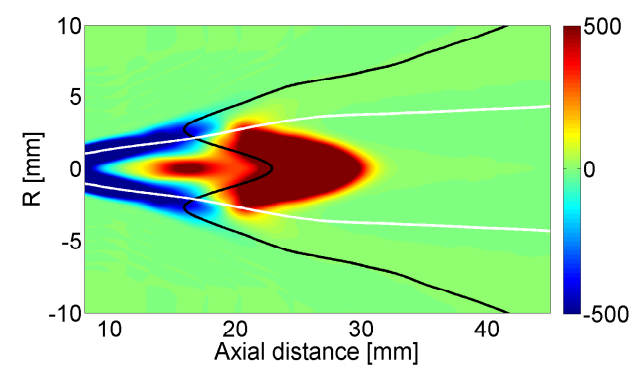

Figure 13: Flame index at $\mathrm{T}_{a m b}=900 \mathrm{~K}$. The white line is the contour of $\mathrm{Z}_{s t}$ and the black line indicate the temperature contour of $1100 \mathrm{~K}$.

Interestingly, this structure is quite similar to previous DNS of lifted flames in heated oxidiser conditions: in an autoigniting hydrogen jet flame [82], and in earlier two-dimensional DNS of lifted flames in heated jets [83]. It differs somewhat from early DNS of a lifted hydrogen flame in non- 
autoignitive conditions [84] in that in the present case the flame base has a non-premixed character; however both simulations agree on the existence of a rich inner premixed core flame.

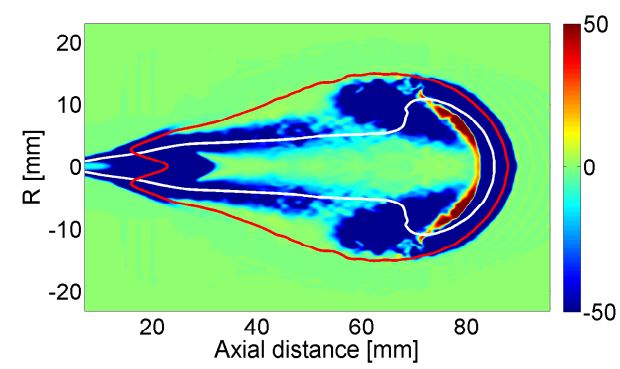

Figure 14: Trailing diffusion flame colored by the flame index at $\mathrm{T}_{a m b}=900 \mathrm{~K}$. The white line is the contour of $\mathrm{Z}_{s t}$ and the red line indicate the temperature contour of $1100 \mathrm{~K}$.

Dec's conceptual model [2] featured a high temperature diffusion-flame which shrouded the rich inner region. The existence of a rich premixed leading edge flame in the core region, as shown in Fig. 13, suggests that the diffusion flame does not burn pure fuel but instead burns products of the rich inner flame. To reveal this shrouding diffusion flame, therefore, the fuel mass fraction in equation 2 is replaced by mass fractions of $\mathrm{CO}, \mathrm{H}_{2}, \mathrm{CH}_{4}$, $\mathrm{CH}_{3}, \mathrm{C}_{2} \mathrm{H}_{2}$ and $\mathrm{CH}_{2}$, which are the major products of the inner rich flame. The resulting flame index, shown in Fig. 14, does indeed exhibit the expected trailing diffusion flame according to the observed negative flame index over most of the flame. The small region of positive flame index behind the jet head is probably the remnants of the premixed burn phase of ignition.

Together, Figs. 13 and 14 support the overall flame structure originally proposed by Dec [2] and refined by Musculus et al. [7]. Importantly, the results show that both premixed and nonpremixed combustion occurs in the 


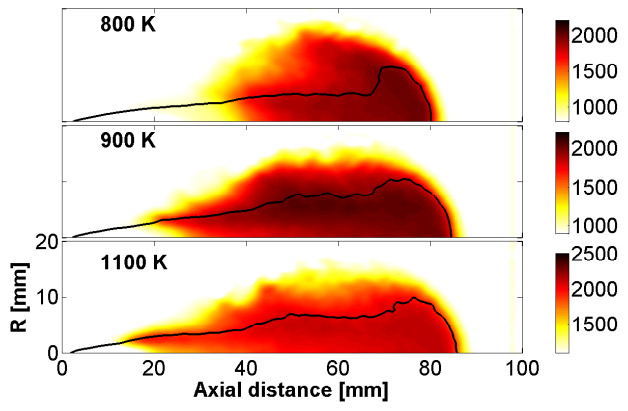

(a) Temperature

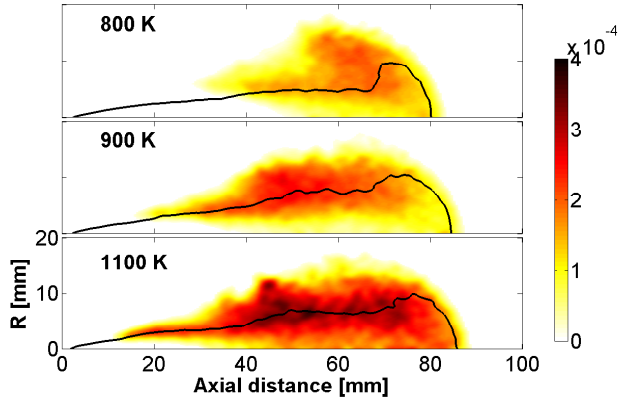

(b) $\mathrm{OH}$

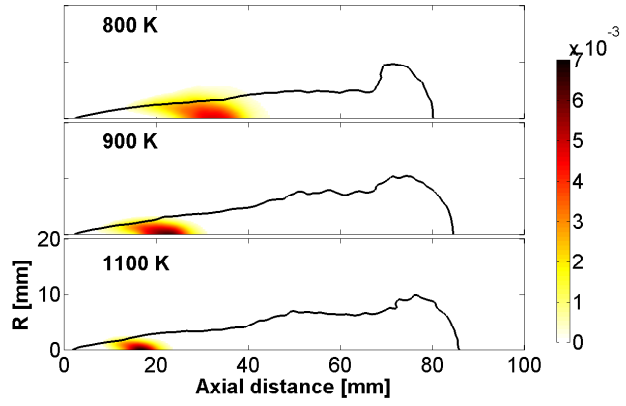

(c) $\mathrm{CH}_{2} \mathrm{O}$

Figure 15: Computed fields of mean mass fraction of (a) temperature, (b) $\mathrm{OH}$ and (c) $\mathrm{CH}_{2} \mathrm{O}$ at $4 \mathrm{~ms}$ after start of injection. The black iso-contours represent the mean stoichiometric mixture fraction. 
same flame, which has implication for selection of appropriate combustion models that can simultaneously account for both types of combustion.

\subsection{Stabilised flame}

\subsubsection{Spatial structure}

To understand the effects of the ambient temperature on the overall flame structure, temperature, $\mathrm{CH}_{2} \mathrm{O}$ and $\mathrm{OH}$ mass fractions at $4 \mathrm{~ms}$ are shown in Fig. 15. Formaldehyde $\left(\mathrm{CH}_{2} \mathrm{O}\right)$ is a product of the first stage of ignition which has frequently been measured using $355 \mathrm{~nm}$ laser-induced fluorescence as a marker of regions where low-temperature (cool-flame) chemistry is underway $[13,71]$. Hydroxyl $(\mathrm{OH})$ is selected as a marker of regions where high-temperature chemistry is active, also in accordance with several experimental studies $[9,11,12]$. In Fig. 15, the black line shows the stoichiometric mixture fraction. Figure 15(a) and 15(b) show that as the ambient temperature is increased, the high temperature reaction zone is elongated and the magnitude of temperature and $\mathrm{OH}$ mass-fraction increases. However, the region of cool-flame chemistry, as suggested by the presence of $\mathrm{CH}_{2} \mathrm{O}$, becomes more compact at higher ambient temperature conditions as presented in Fig. 15(c). For the $800 \mathrm{~K}$ case, the mass fractions of $\mathrm{OH}$ and $\mathrm{CH}_{2} \mathrm{O}$ are approximately a factor of 2 and 1.5 lower compared to those of the $1100 \mathrm{~K}$ case, respectively. The axial starting points of regions of both high formaldehyde and hydroxyl are shorter for the higher ambient temperature case. Therefore, the ambient temperature has a significant effect on the location and shape of high temperature reaction zones and the cool flame regions. 

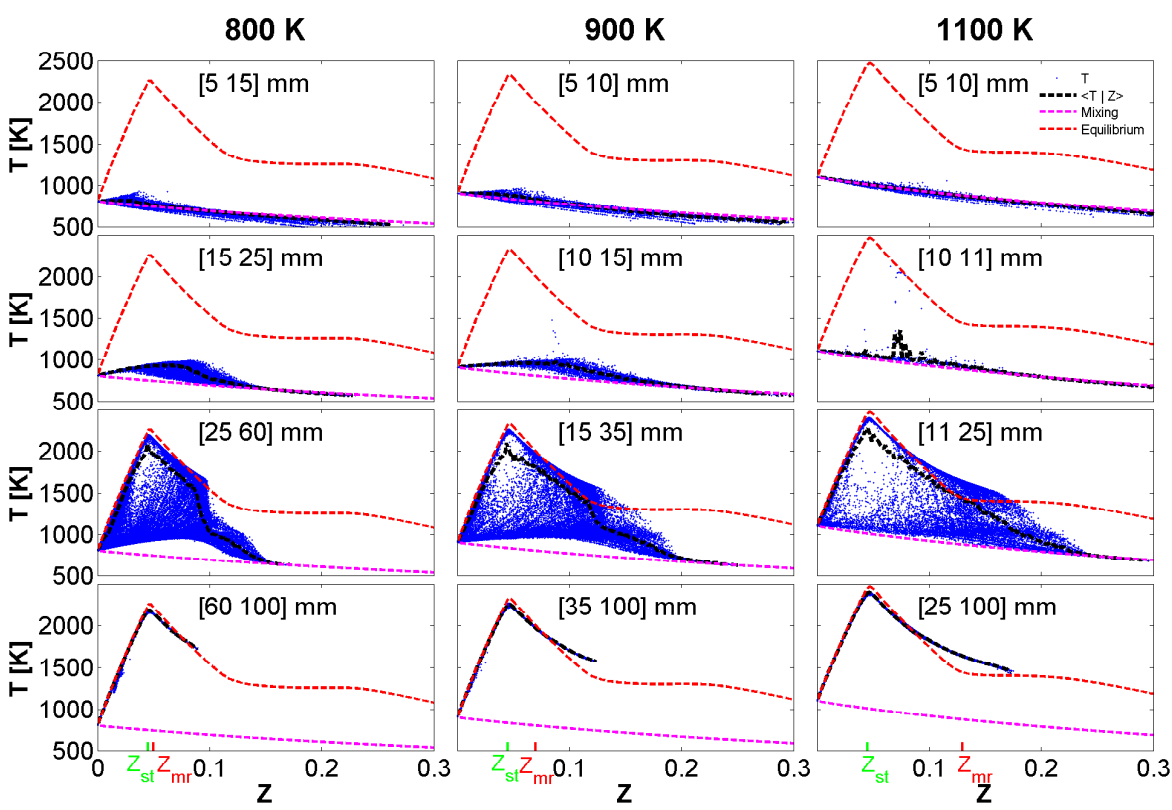

Figure 16: Spatial variations of scatter plots of $\mathrm{T}$ at different ambient $\mathrm{T}$ conditions. The black dashed line is the mean $\mathrm{T}$ conditional on $\mathrm{Z}$.

\subsubsection{Structure in mixture-fraction space}

Figure 16 shows scatter plots of temperature versus mixture fraction for a sequence of windows of spatial locations corresponding to a progression through the stabilised flame at $4 \mathrm{~ms}$ for the three ambient temperatures. (Note that each ambient temperature condition uses different windows which have been selected to expose the relevant stages in each flame.) Some similar features are observed as for the temporal evolution shown in Fig. 2. On the top row, representing the axial window closest to the nozzle, the mixture states are close to the mixing line. A definite first stage of ignition is noted in the second row, representing an axial window further downstream, for ambient temperatures of $800 \mathrm{~K}$ and $900 \mathrm{~K}$. However, the first stage of ignition 
in the $1100 \mathrm{~K}$ case is either very short in spatial extent, overlapping in spatial extent with the high-temperature combustion, or entirely absent. This is different to what was observed for the ignition event shown in Fig. 2 where there was a clear first stage at very rich mixtures at this temperature. A possible explanation is that mixing from the hot products brings forward the main combustion and it overtakes the first stage ignition. In the third row, a range of states co-exists between the mixing line and a fully burning flame and there are significant conditional fluctuations, before finally in the bottom row all states are fully burning, presumably in a mixing-controlled mode, and are close to the equilibrium line with minimal conditional fluctuations.

For the $900 \mathrm{~K}$ and $1100 \mathrm{~K}$ cases, there are significant regions where temperatures are super-equilibrium. This is possible because of mixing from regions of higher temperature.

Figure 17 shows scatter plots of $\mathrm{R}-\mathrm{OO}, \mathrm{H}_{2} \mathrm{O}_{2}$, and $\mathrm{OH}$ for the same spatial windows in the $900 \mathrm{~K}$ case. As mentioned earlier, R-OO is a key intermediate in the first stage ignition, while $\mathrm{OH}$ marks high temperature second-stage ignition reactions. $\mathrm{H}_{2} \mathrm{O}_{2}$ is a key product of the first stage ignition whose breakdown has been suggested as a marker of the beginning of the second stage ignition and thermal runaway [85]. R-OO appears very early in the flame and then progressively moves to richer mixtures, indicating a progression of ignition. $\mathrm{H}_{2} \mathrm{O}_{2}$ is observed to occur in regions of high R-OO and also extends somewhat into leaner mixtures once R-OO disappears. Although a detailed reaction pathway analysis has not been conducted, this probably results from direct molecular elimination of R-OO leading to an olefin and $\mathrm{HO}_{2}$ [85] which subsequently reacts via various pathways to form $\mathrm{H}_{2} \mathrm{O}_{2}$. OH 

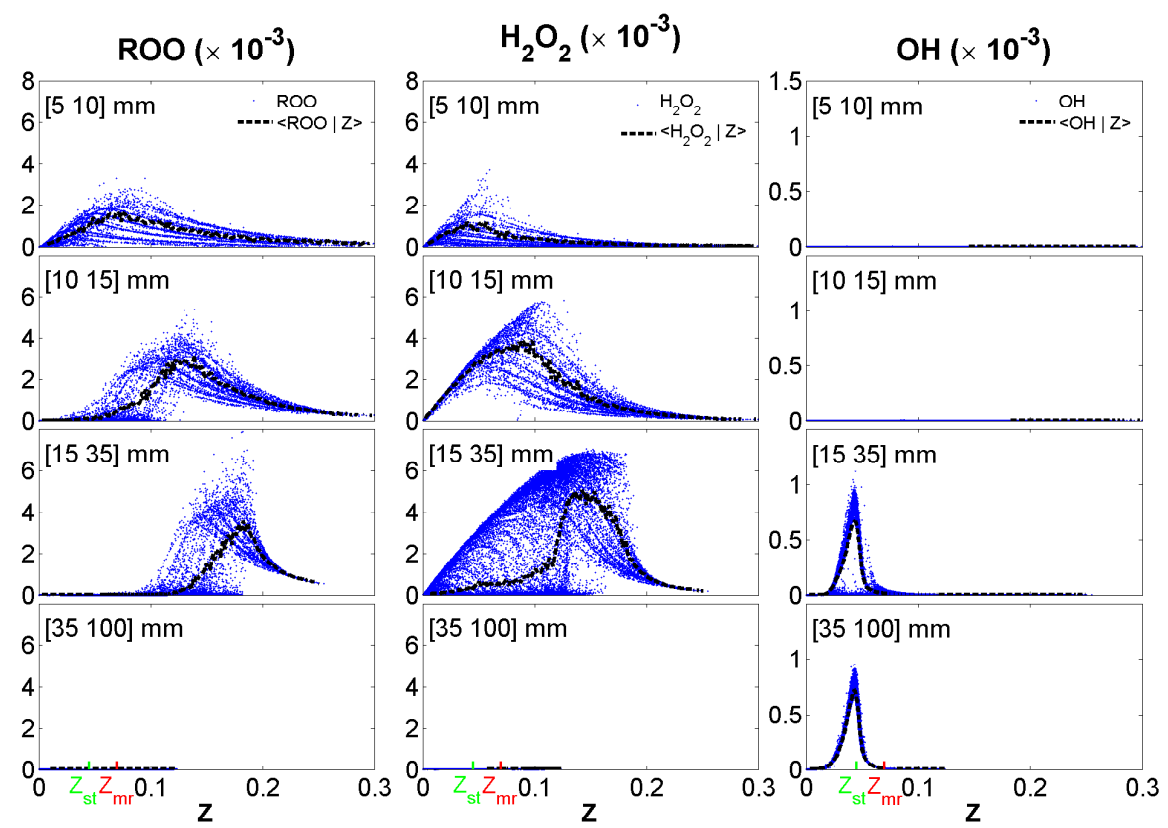

Figure 17: Spatial variation of scatter plots of different species at $\mathrm{T}_{a m b}=900 \mathrm{~K}$ and 4 ms. The black dashed line is the mean species mass fraction conditional on $\mathrm{Z}$.

does not occur initially in significant amounts in the first two (upstream) rows. In the third row the distribution is bi-modal suggesting some mixtures have undergone second stage ignition while others have not. At the final and most downstream station a mono-modal and narrow $\mathrm{OH}$ distribution is observed similar to that observed in conventional diffusion flames, e.g. [86].

To further elaborate the above-described spatial structure, the centreline values for $\mathrm{CH}_{2} \mathrm{O}, \mathrm{R}-\mathrm{OO}, \mathrm{OH}$ and $\mathrm{T}$ (normalised by their maximum) are shown in Fig. 18. One can notice that R-OO and $\mathrm{CH}_{2} \mathrm{O}$ overlap to some extent, but peak at different locations. $\mathrm{CH}_{2} \mathrm{O}$ occurs during first stage ignition and is depleted towards second ignition, which is in agreement with the findings of Ref. [7]. 


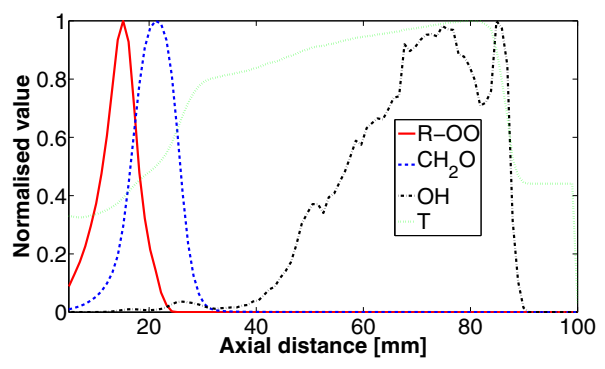

Figure 18: Centreline value for $\mathrm{CH}_{2} \mathrm{O}, \mathrm{ROO}, \mathrm{OH}$ and $\mathrm{T}$ at $900 \mathrm{~K}$ ambient temperature conditions.

\subsubsection{Turbulence parameters}

The steady flame is now discussed in terms of the local ratios of turbulence and chemistry timescales, which control regimes of flame-turbulence interaction, e.g. [87]. The Damköhler number (Da) is the ratio of the integral timescale and a chemical timescale while the Karlovitz number (Ka) is the ratio of the chemical timescale to the Kolmogorov timescale. If Da is much less than unity, then chemistry is much slower than turbulent mixing. This may lead to a chemically rate-limited well-stirred reactor regime in which fuel, oxidiser, and products are micro-mixed rapidly, resulting in a distributed reaction zone. Alternatively, depending on the local boundary conditions for mixing, local or global extinction may result. At the other extreme, when $\mathrm{Ka}$ is less than unity, which at high Reynolds number implies Da is much larger than unity, all turbulence timescales are longer than the chemical time. In this situation combustion becomes mixing rate-limited, and local states become similar to those found in a laminar flame. In the region between unity Da and unity Ka, a range of small turbulent scales are fast enough to penetrate and disrupt the chemistry, while the large scales 
cannot. Due to the fact that experimental measurements of turbulence parameters in diesel engine sprays have not, to our knowledge, been performed, there is little information as to what regimes of Da and Ka might be present.

Table 3: Chemical time scales.

\begin{tabular}{llll}
\hline $\mathrm{T}_{a m b}(\mathrm{~K})$ & $\tau_{c, 1}$ & $\tau_{c, 1} / \tau_{c, 2}$ & $\tau_{c, 1} / \tau_{c, 3}$ \\
\hline 800 & 1.41 & 3.62 & 99.6 \\
900 & 0.49 & 2.87 & 14.9 \\
1100 & 0.21 & 3.25 & 4.3 \\
\hline
\end{tabular}

To evaluate Ka and Da, characteristic timescales for the ignition need to be established. There are several possible definitions, and three definitions are examined here. The first definition has already been introduced: it is simply the ignition delay of the main ignition at the most reactive mixture fraction, $\tau_{c, 1}$, which is determined from the time of the maximum rate of temperature rise. Another timescale involved is the delay between the first and second ignition, $\tau_{c, 2}$. This is determined by the time difference between the peak rates of temperature rise in the first and second ignitions. The final definition considered here is an inner timescale corresponding to the high temperature reactions and thermal runaway which is determined, once again for the most reactive mixture fraction, as:

$$
\tau_{c, 3}=\frac{T_{b}-T_{u}}{d T / d t_{\max }}
$$

where $T_{b}$ and $T_{u}$ are the burned and unburned temperatures, respectively, and $d T / d t$ is the rate of change of temperature. This timescale is relevant 
to rapid exothermic reactions around the time of maximal heat-release rate. Figure 19 depicts these timescales in a $900 \mathrm{~K}$ homogeneous reactor case. Table 3 presents $\tau_{c, 1}$ and the ratios $\tau_{c, 1} / \tau_{c, 2}$ and $\tau_{c, 1} / \tau_{c, 3}$ for the three temperature conditions of $800 \mathrm{~K}, 900 \mathrm{~K}$ and $1100 \mathrm{~K}$. Damköhler numbers formed from $\tau_{c, 1}, \tau_{c, 2}$ and $\tau_{c, 3}$ are denoted $\mathrm{Da}_{1}, \mathrm{Da}_{2}$ and $\mathrm{Da}_{3}$, respectively. The various Karlovitz numbers are denoted similarly. It is important to understand that all of these estimated chemical and turbulence timescales at best represent global, mean, values, similar to the related quantities frequently used in turbulent premixed combustion, for example. In reality, local timescales of both turbulence and chemistry can fluctuate significantly, such that local behaviours can depart from those suggested by global values - for example see Echekki and Chen [64] and Yoo et al. [82]. Nonetheless, global parameters can still be useful, at least until such time as more detailed local information becomes available.

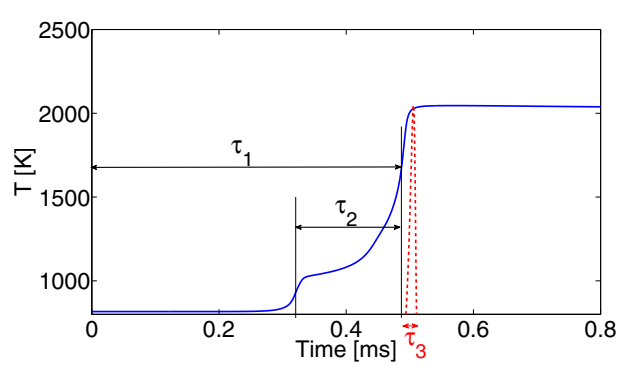

Figure 19: Definitions of chemical time scale.

Figure 20 shows contours of $\mathrm{Da}_{1}=0.1$ and 1.0, and $\mathrm{Ka}_{1}=1000$ and 100 for the $900 \mathrm{~K}$ Spray A baseline case at $4 \mathrm{~ms}$. The base is here identified with $\mathrm{OH}$ mass fraction of $14 \%$ of its maximum. It is observed that $\mathrm{Da}_{1}$ is less than unity in a large region. It is between 0.1 and 1 around the flame 


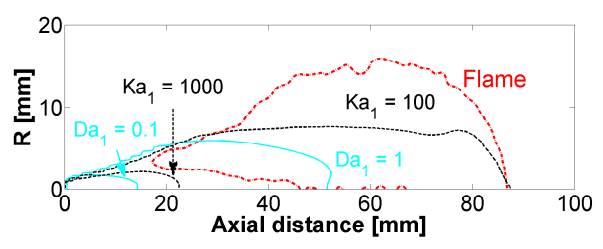

Figure 20: Definition 1 of Damköhler and Karlovitz number at $\mathrm{T}_{a m b}=900 \mathrm{~K}$ and $4 \mathrm{~ms}$. The cyan solid lines represent $\mathrm{Da}_{1}$ and the black dashed lines indicate $\mathrm{Ka}_{1}$. The red dash-dot line is the existence of the flame.

base and much less than unity further upstream. Thus, during the time of the ignition delay, significant large scale turbulent mixing occurs. Furthermore, considering the $\mathrm{Ka}$, it is observed that the region $\mathrm{Ka}_{1}>100$ is even larger, indicating that small scale mixing is quite rapid compared with ignition. Notably, the region of $\mathrm{Ka}_{1}>1000$, which corresponds to extremely intense small scale mixing, almost extends up to the flame base as identified by the $\mathrm{OH}$ contour, and referring back to Fig. 8, the region where low temperature chemistry is occurring is entirely within the $\mathrm{Ka}_{1}>1000$ region. The moderately small $\mathrm{Da}_{1}$ at the flame base suggests that flame-turbulence interactions are significant, and may control the flame stabilisation - i.e. the flame cannot move further upstream because mixing rates out of early igniting regions (here represented by particles) are too large. This is consistent with the earlier discussion of the transport budgets of $\mathrm{Y}_{O H}$.

$\mathrm{Da}_{2}$ is about three times as high as $\mathrm{Da}_{1}$, while $\mathrm{Ka}_{2}$ is correspondingly about one third of $\mathrm{Ka}_{1}$. It is clear therefore from Fig. 20 that turbulent mixing at the integral scale is important between the stages of ignition, and that small scale mixing is even more important. The time scale $\tau_{c, 3}$ is much shorter, however, and the region of $\mathrm{Da}_{3}<1$ is smaller than that of $\mathrm{Da}_{1}<$ 
0.1 on the figure, so that integral scales would not be sufficiently fast to interact with thermal runaway once it has already begun. However, $\mathrm{Ka}_{3}$ is still significantly larger than unity in the region of the flame base, suggesting that small-scale turbulence can strongly interact with even the inner structure of the flame during thermal runaway.

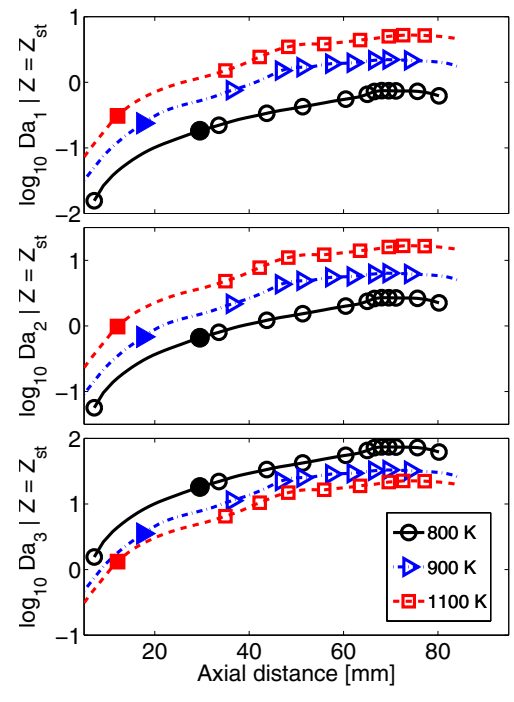

(a) Damköhler number

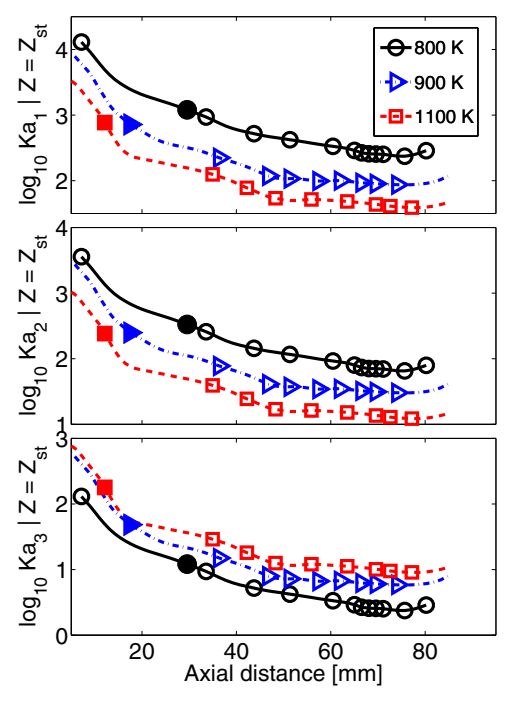

(b) Karlovitz number

Figure 21: Different definitions of (a) Damköhler number and (b) Karlovitz number conditional on $\mathrm{Z}=\mathrm{Z}_{\text {st }}$ at different ambient temperature conditions. The solid markers show the corresponding lift-off lengths.

To present the same information in a more quantitative fashion, Fig. 21(a) plots the logarithm of $\mathrm{Da}_{1}, \mathrm{Da}_{2}$ and $\mathrm{Da}_{3}$ on the mean stoichiometric contour versus axial distance, for each of the three cases of ambient temperature. The lift-off length is marked with a solid marker. Similarly, Fig. 21(b) plots Ka $\mathrm{Ka}_{2}$ and $\mathrm{Ka}_{3}$. There are significant differences in the parameter regimes 
between the cases of different temperatures, corresponding to the shorter chemical ignition delay time and time period between first and second ignition in the higher temperature conditions, but the longer timescale of the thermal runaway. $\mathrm{Da}_{1}$ is between 0.1 and 1.0 upstream of the lift-off length in all three cases, and in the $800 \mathrm{~K}$ case, the entire stoichiometric contour has $\mathrm{Da}_{1}<1$. $\mathrm{Ka}_{1}$ is around 1000 or greater in the region of the lift-off length, and never falls below 100 in the $800 \mathrm{~K}$ case. In all three temperature cases, the $\mathrm{Da}_{3}$ is greater than unity across the flame. This is significant for well-mixed modelling. A well-mixed model should only be effective if the $\mathrm{Da}_{3}$ is less than unity, because within the time $\tau_{c, 3}$, a region can go from being on the cusp of ignition to being close to equilibrium thus generating a significant scalar fluctuation compared with other regions that have not yet ignited. Such fluctuations will only homogenise by mixing if $\mathrm{Da}_{3}$ is less than unity. However $\mathrm{Ka}_{3}$ is also uniformly greater than unity, which suggests that direct interactions between regions going through thermal runaway and a range of small turbulence scales with the flame are expected. It may be the case that if large-eddy simulations are performed instead of RANS, that the grid could be chosen fine enough to compute all the scales with $\mathrm{Da}_{3}>1$ directly (where here we mean the Da applied to the smallest resolved scales), such that a well-mixed approximation might then be reasonably applied at the sub-grid level. Future investigations on this point are suggested.

Interestingly, while the lift-off length moves downstream for decreasing ambient temperature, $\mathrm{Da}_{1}$ and $\mathrm{Da}_{2}$ are roughly the same order of magnitude, owing to the increase of the turbulence timescale with downstream distance. As $\mathrm{Da}_{1}$ is less than unity at the lift-off location, while $\mathrm{Da}_{2}$ is around unity, it 
is possible that turbulent mixing could be an important mechanism of flame stabilisation. Earlier works have suggested that lifted flames in atmospheric conditions may be stabilised at the location of where a critical scalar dissipation rate occurs [60]. The evidence for those flames appeared to suggest that dissipation rates were insufficient to support such a mechanism, however in the present situation, the low Damköhler number suggests that such a mechanism is certainly possible. The model also suggests Ka is high, which may be practically significant too, but it is important to recognise that there is no direct Ka dependence of the model outcomes, as small scales are not represented.

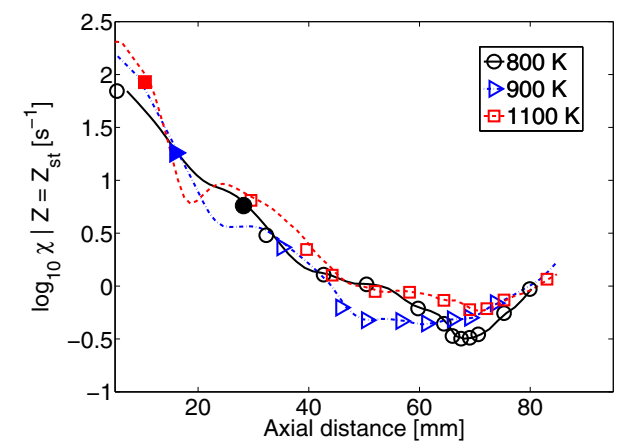

Figure 22: Scalar dissipation rate $(\chi)$ conditional on $\mathrm{Z}=\mathrm{Z}_{\text {st }}$ at different ambient $\mathrm{T}$ conditions. The solid markers show the corresponding lift-off lengths.

Figure 22 shows the scalar dissipation rate versus downstream distance, and once again lift-off length is marked with a filled symbol. Scalar dissipation rates in the vicinity of the lift-off are not large, around $10-100 \mathrm{~s}^{-1}$. These are somewhat below the critical scalar dissipation rate at which a laminar flamelet does not ignite, around $400 \mathrm{~s}^{-1}$ in the $900 \mathrm{~K}$ case. However, the relevance of the flamelet critical scalar dissipation rate as a controlling 
parameter in the present conditions is questionable. In the flamelet concept, combustion occurs in a mixing layer which has boundary conditions of pure fuel and oxidiser. This certainly occurs in the near field of a jet, and as a result mixture fraction PDFs have a bi-modal character, and the scalar variance is the order of $\widetilde{Z}(1.0-\widetilde{Z})$. However, in the present cases in which the flame stabilises between $X / D$ of 130 to 340 , the probability of observing pure fuel and oxidiser inside the jet diminishes to nearly zero, and mixture fraction fluctuations are very small, which leads to the relatively small scalar dissipation rates that are observed. However, the mixing rate itself is still large, and this can result in significant loss of heat and radicals from igniting regions (in this case, particles), despite these regions having a similar mixture fraction to other non-igniting regions.

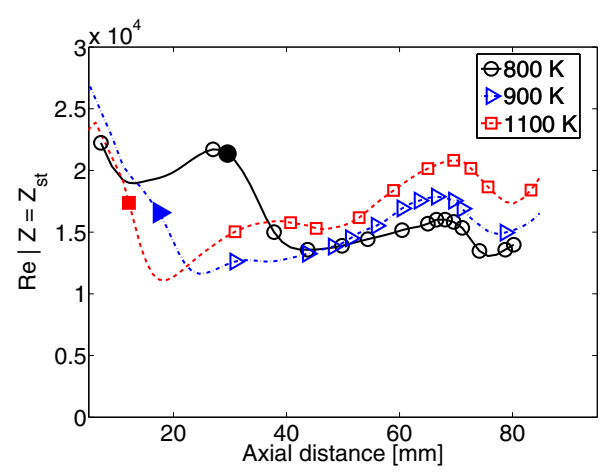

Figure 23: Turbulent Reynolds number conditional on $\mathrm{Z}=\mathrm{Z}_{s t}$ at different ambient $\mathrm{T}$ conditions. The solid markers show the corresponding lift-off lengths.

Another parameter of interest is the turbulence Reynolds number, $\mathrm{Re}_{t}$, which is plotted in Fig. 23. The turbulence Reynolds number is between 10,000 and 20,000 and as expected it is only weakly dependent on downstream distance (after the flame location, at least) and on the ambient tem- 
perature. This is important as it shows that the jet is indeed very turbulent despite the relatively small physical dimensions of the nozzle. Such Reynolds numbers are well beyond the range of present combustion DNS capabilities, and are probably also beyond the range of DNS of non-reacting flows. For example, a recent large scale DNS of hydrogen-air combustion achieved turbulent Reynolds number approaching 1,000 but this required around 40 million CPU hours $[88,89]$. It is conceivable that with exascale computing (i.e. $10^{18}$ floating point operations per second), expected by the end of this decade, Reynolds numbers approaching 10,000 might be achievable. However, given the added complexity of large hydrocarbon fuels and the huge axial extent of a diesel jet flame, it could be suggested that a DNS of a practical diesel spray flame is at least many decades away, thus motivating the continued development of more practically applicable models such as investigated in this paper.

The TPDF method does not assume any form for the scalar PDFs, unlike well-mixed models, which assumes them to be $\delta$-functions, and flamelet and related approaches, which assume particular forms depending on the scalar being considered. The left plot of Fig. 24 shows the PDF of mixture fraction conditional on the mixture fraction mean being stoichiometric, for different axial stations in the $900 \mathrm{~K}$ case. The mixture fraction PDF is close to monomodal, however, it still has a finite width. The extent of the error that results from ignoring these fluctuations and approximating the PDF as a $\delta$-function hinges on the extent that species mass fractions and temperature depend on mixture fraction. Taking equilibrium as a simple and unambiguous example case for this dependence, given the stoichiometric mixture fraction is 0.045, 
the temperature of the equilibrium products would increase from ambient to the adiabatic stoichiometric temperature of $2332 \mathrm{~K}$, and the PDF is clearly non-zero over this range, so significant temperature fluctuations would result.

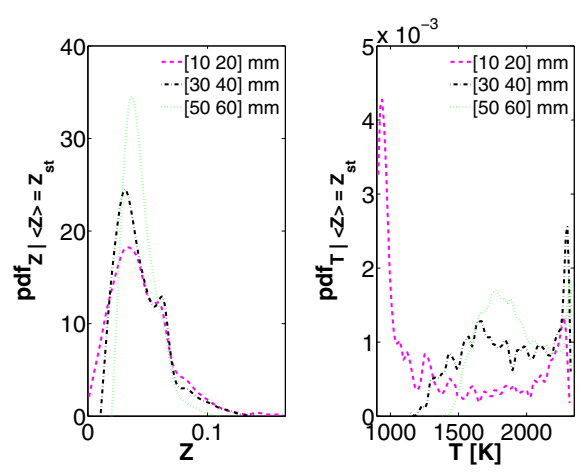

Figure 24: PDFs of $\mathrm{T}$ and $\mathrm{Z}$ conditional on $\mathrm{Z}=\mathrm{Z}_{s t}$ at $\mathrm{T}_{a m b}=900 \mathrm{~K}$.

Temperature PDFs are shown in the right plot of Fig. 24, once again conditional on the mean stoichiometric mixtures. Unlike mixture fraction, the temperature PDF is not mono-modal over the axial extent considered. It is strongly bi-modal between 10 and $20 \mathrm{~mm}$ with peaks corresponding to the mixing line and equilibrium. Further downstream the low-temperature peak broadens and increases in temperature, but the bi-modal nature is retained. Interestingly, referring back of Fig. 16, the temperature PDF conditional on mixture fraction is actually quite narrow at stations past $35 \mathrm{~mm}$, suggesting that the observed temperature fluctuations are simply a result of the mixture fluctuations after about $35 \mathrm{~mm}$. An important point to be made here is that the temperature PDF is not a $\delta$-function, and is not even monomodal, which invalidates the underlying assumption of the well-mixed model and some flamelet models which assume a $\delta$-function for a progress variable PDF. Furthermore, again consulting Fig. 16, it is clear that the PDFs 
of temperature and mixture-fraction are definitely not independent, which may invalidate assumptions made in some flamelet-based models also. It is clear however that the assumption of a $\delta$-function of the mixture-fractionconditional temperature PDF would be better supported, however to use this fact, a method would then be needed to invert an integral equation to obtain the conditional mean from the known mixture fraction PDF and the known mean temperature [90-92].

\subsection{Dimensionality analysis}

A key question that arises in combustion modelling is the dimensionality of the thermochemical state-space. Low-dimensional state-spaces lend themselves to considerably cheaper modelling approaches, for example in various flamelet modelling approaches [93, 94]. The chemical dimensionality analysis in composition space has been conducted by Yang et al. [95] in open laboratory flames, where a non-premixed $\mathrm{CO} / \mathrm{H}_{2}$ jet flame and a ethylene lifted jet flame were studied using empirical low-dimensional manifolds (ELDMs). Two methods were used, including principal component analysis (PCA) [96] and multivariate adaptive spline regression (MARS) [97], respectively. It is now applied to Spray A with a much larger chemical mechanism to conduct the dimensionality analysis at engine conditions.

To examine the departure of the $i^{t h}$ composition $v_{i}$, a normalised rootmean square (RMS) departure, $\epsilon_{i}$, is defined as $\epsilon_{i}=\sqrt{\left\langle v_{i}^{\prime 2}\right\rangle} / \sigma_{i}$, where $\langle\cdot\rangle$ denotes the ensemble average over $N$ observations and $\sigma_{i}$ is the standard deviation of $v_{i}^{\prime}$. Figure 25 presents the $\epsilon_{i}$ of selected species versus the number of dimensions $n_{r}$ with PCA and MARS at the $900 \mathrm{~K}$ condition. The red dotted line indicates the $20 \%$ departure level and black dashed line is the 
$5 \%$ level. For the major species in the first row of Fig. 25, a small number of dimensions, usually less than 5, are needed to reach the $5 \%$ departure from the PCA ELDM. One also can notice that $\epsilon_{i}$ decays quickly with increased $n_{r}$. In contrast, for the minor species in the second row, more than 10 dimensions are required to reach the $5 \%$ departure with the MARS method. This is mainly because of the large size of chemical mechanism used in this study. It is also noted that MARS consistently performs better than PCA because MARS can minimize the departures normal to the plane PCA manifold if the ELDM is curved.
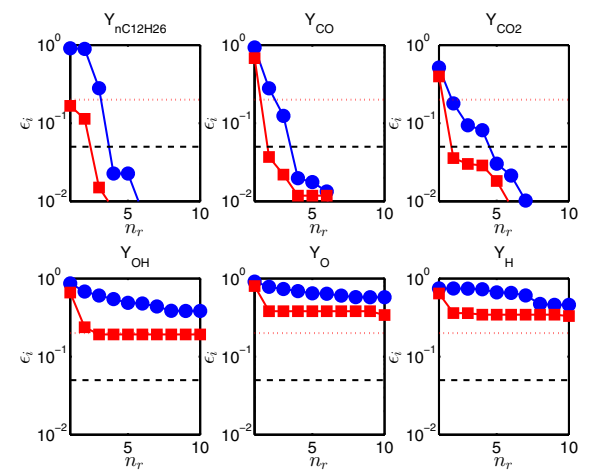

Figure 25: Normalized RMS departure $\epsilon_{i}$ of different species mass fractions from PCA and MARS (circles: PCA; squares: MARS). The dashed line shows the $5 \%$ level and the dotted line shows the $20 \%$ level at $\mathrm{T}_{a m b}=900 \mathrm{~K}$.

The illustrations of the curved MARS ELDMs $\phi_{C O}^{M}\left(\eta_{1}, \eta_{2}\right)$ and $\phi_{O H}^{M}\left(\eta_{1}, \eta_{2}\right)$ with sample points conditioned on different $\eta_{1}$ are shown in Figure 26, where $\eta_{1}$ and $\eta_{2}$ are the first and the second principal components, respectively. The red curves indicate the departure of the sample points from the manifold. One can see that the manifold of the major specie CO is close to a plane manifold with relatively small RMS departures. In contrast, the manifold 

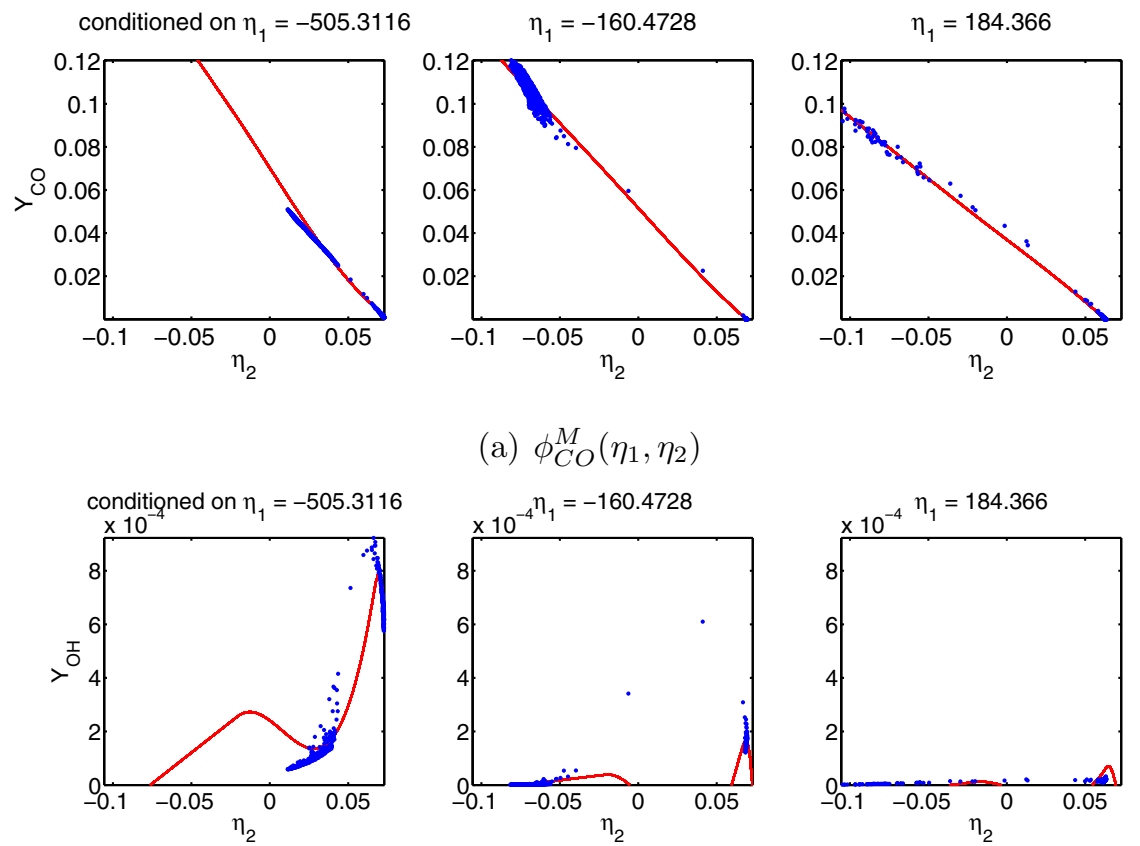

(b) $\phi_{O H}^{M}\left(\eta_{1}, \eta_{2}\right)$

Figure 26: The ELDMs $\phi_{i}^{M}\left(\eta_{1}, \eta_{2}\right)$ (top-left in each subfigure) and $\phi_{i}^{M}\left(\eta_{1}, \eta_{2}\right)$ conditioned on $\eta_{1}$ from MARS with corresponding sample points $\mathrm{Y}_{i}\left(\eta_{1}, \eta_{2}\right)$ for (a) $\mathrm{CO}$ and (b) $\mathrm{OH}$, respectively. The color on the surface is coded by $\mathrm{Y}_{i}$ at $\mathrm{T}_{a m b}=900 \mathrm{~K}$. 
of the minor specie $\mathrm{OH}$ shows much more curved manifold and the sample points have large departures.

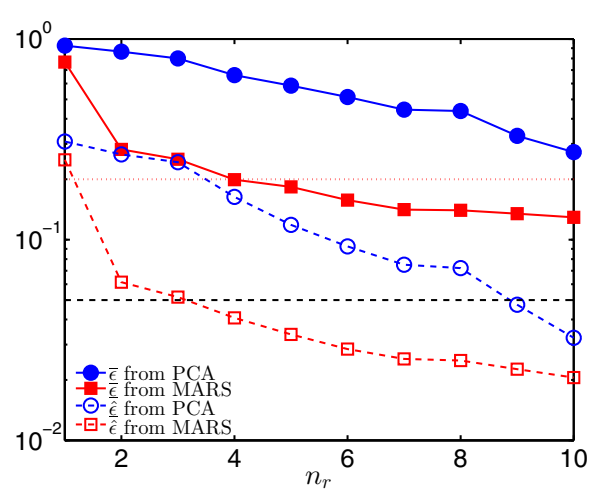

Figure 27: Unscaled mean RMS departure $\bar{\epsilon}$ and scaled mean RMS departure $\overline{\hat{\epsilon}}$ over all the species mass fractions from PCA and MARS. The dashed line shows the $5 \%$ level and the dotted line shows the $20 \%$ level at $\mathrm{T}_{a m b}=900 \mathrm{~K}$.

To further evaluate the overall RMS departures from PCA and MARS, a mean RMS departure $\bar{\epsilon}$ is defined as the average of $\epsilon_{i}$ over all the species. A mean scaled RMS departure $\overline{\hat{\epsilon}}$ is also introduced to prevent small departures in minor species from making a disproportional contribution, where $\hat{\epsilon}_{i}=$ $\sqrt{\left\langle v_{i}^{\prime 2}\right\rangle} / \max \left(\sigma_{i}, 10^{-3}\right)$ is the scaled normalized RMS departure for the $i^{\text {th }}$ composition. The unscaled and scaled mean RMS departures are presented in Fig. 27. One can notice from the scaled mean RMS departure that nine dimensions are required for PCA compared to three dimensions for MARS. Moreover, the unscaled mean RMS departure is much larger than the scaled one for a given $n_{r}$. Overall, this large mechanism requires more dimensions compared to the previous studied smaller chemical mechanisms (ethylene and hydrogen) [95] in order to obtain an accurate ELDM. 


\section{Summary}

Relating to the characteristics of ignition and combustion, the following findings were inferred from the model results:

- The first stage ignition appears to be very resilient to turbulence and occurs rapidly in a region of very high Karlovitz number and low Damköhler number. It occurs first on the lean side and progresses towards richer mixtures and towards higher Ka and lower Da. In the stabilised flame, the first stage of ignition is still evident upstream of the main flame.

- The main ignition occurs first in rich mixtures. Analysis of the main ignition showed that ignition occurred in richer conditions than suggested by the most reactive mixture fraction. This was attributed firstly to entrainment and mixing of first-stage ignition products from leaner regions and secondly to high gradients at the jet head which prevented those leaner regions from undergoing second stage ignition.

- The leading edge of the flame moves rapidly from the ignition location towards its downstream stabilised point. The initial speeds are order $200 \mathrm{~m} / \mathrm{s}$ which is much faster than expected turbulent flame speeds, suggesting that the flame initially moves as a spontaneous ignition front, moving according to gradients of ignition delay and/or residence time as imposed by the local mixture and mixing conditions. Later, however, the flame stabilises in a region of lower velocity, at around $10 \mathrm{~m} / \mathrm{s}$. Although much higher than an expected laminar flame velocity, it is not impossible that turbulent transport plays a role in 
the stabilisation, as turbulent velocity fluctuations are the same order in this region. The analysis of convection-diffusion-reaction budget terms indicates that the flame is stabilised by autoignition (as opposed to premixed flame propagation), but that a balance between reaction, downstream convection and turbulent diffusion exists at the stabilisation point, suggesting that turbulent macro-mixing is a key factor controlling stabilisation. Analysis of the flame index at the flame location suggests essentially a non-premixed, autoignitive stabilisation mode. A trailing premixed flame is observed in the inner rich region while a trailing diffusion flame is observed to shroud the outer region of the flame. This structure supports the original suggestions of Dec [2] and the refinements suggested in Musculus et al. [7].

- The stabilised flame is unlike a typical laboratory lifted jet flame. There is a first stage of ignition that occurs quite close to the nozzle, while the high temperature region occurs much further downstream (many tens of jet diameters). There is a clear sequence of different layers of species which are, at least in part, not spatially overlapping (by many jet diameters). The mixture-fraction PDF is of a marching type and monomodal at the flame stabilisation location. These features suggest that a conceptual model of a diesel flame as a collection of thin reacting mixing layers with boundary conditions of pure fuel and oxidiser is invalid. At a minimum it suggests that local mixture boundary conditions are highly dependent on the position in the jet and time, and possibly that combustion itself occurs in a semi-distributed fashion without a strongly preferred direction of large gradients as in a mixing layer. 
- The leading edge of the high-temperature flame exists in a region which has a turbulent Reynolds number order $10^{4}$, a Damköhler number order 0.1 - 1.0, and a Karlovitz number of order 1000. This suggests the high temperature stabilisation region is highly turbulent, and that turbulence is likely to significantly affect the combustion, raising questions for approaches that either neglect turbulent fluctuations, or treat them with fast chemistry approximations. Low-temperature reactions occur in regions of even higher Ka and lower Da. On the other hand, at the leading edge of the hot flame, the estimated scalar dissipation is well below the critical dissipation rate which prevents ignition in a counterflow.

- Analysis of the chemical dimensionality shows that MARS consistently performs better than PCA. At least three dimensions are required to capture major species with MARS; more dimensions are required to capture minor species.

In closing, it is worth reminding that the present analysis is based on results from a RANS-based model. While an effort has been made to target questions of global flame behaviour which RANS could be reasonably expected to represent, all models have errors and uncertainties. It is hoped that the present work could inspire follow-up experimental, DNS and perhaps LES studies to further investigate the questions raised here.

\section{Acknowledgments}

Y. Pei acknowledges the support of AusAID via its Australian Leadership Awards program. This work was supported by the Australian Research 
Council. The research was also supported by access to computational resources on the Australian NCI National Facility through the National Computational Merit Allocation Scheme and Intersect, and the UNSW Faculty of Engineering cluster. This work was also funded by U.S. DOE's Office of Vehicle Technologies, Office of Energy Efficiency and Renewable Energy under contract No. DE-AC02-06CH11357. The contribution from Cornell University is based upon work supported by the US DOE, Office of Science, Office of Basic Energy Sciences under Award Number DE-FG02-90ER14128.

\section{References}

[1] J. E. Dec, Advanced compression-ignition engines - understanding the in-cylinder processes, Proc. Combust. Inst. 32 (2) (2009) 2727-2742.

[2] J. E. Dec, A conceptual model of DI diesel combustion based on lasersheet imaging, SAE Trans. (1997), 970873106.

[3] R. D. Reitz, Directions in internal combustion engine research, Combust. Flame 160 (1) (2013) 1-8.

[4] J. E. Dec, R. E. Canaan, PLIF imaging of NO formation in a DI diesel engine, SAE Trans. 107 (3) (1998) 176-204.

[5] S. Kook, C. Bae, P. C. Miles, D. Choi, L. M. Pickett, The influence of charge dilution and injection timing on low-temperature diesel combustion and emissions, SAE Trans. 114 (4) (2005) 1575-1595.

[6] C. A. Idicheria, L. M. Pickett, Soot formation in diesel combustion under high-EGR conditions, SAE Trans. 114 (4) (2005) 1559-1574. 
[7] M. P. Musculus, P. C. Miles, L. M. Pickett, Conceptual models for partially premixed low-temperature diesel combustion, Prog. Energy Combust. Sci. 39 (2) (2013) 246-283.

[8] L. Pickett, G. Bruneaux, R. Payri, Engine Combustion Network, http://www.ca.sandia.gov/ecn (2015).

[9] L. M. Pickett, C. L. Genzale, G. Bruneaux, L.-M. Malbec, L. Hermant, C. Christiansen, J. Schramm, Comparison of diesel spray combustion in different high-temperature, high-pressure facilities, SAE Int. J. Engines 3 (2) (2010) 156-181.

[10] L. M. Pickett, J. Manin, C. L. Genzale, D. L. Siebers, M. P. Musculus, C. A. Idicheria, Relationship between diesel fuel spray vapor penetration/dispersion and local fuel mixture fraction, SAE Int. J. Engines 4 (1) (2011) 764-799.

[11] J. Benajes, R. Payri, M. Bardi, P. Martí-Aldaraví, Experimental characterization of diesel ignition and lift-off length using a single-hole ECN injector, Appl. Therm. Eng. 58 (1) (2013) 554-563.

[12] P. M. Lillo, L. M. Pickett, H. Persson, O. Andersson, S. Kook, Diesel spray ignition detection and spatial/temporal correction, SAE Int. J. Engines 5 (3) (2012) 1330-1346.

[13] S. A. Skeen, J. Manin, L. M. Pickett, Simultaneous formaldehyde PLIF and high-speed schlieren imaging for ignition visualization in highpressure spray flames, Proc. Combust. Inst. 35 (3) (2015) 3167-3174. 
[14] M. Meijer, B. Somers, J. Johnson, J. Naber, S.-Y. Lee, L. M. Malbec, G. Bruneaux, L. M. Pickett, M. Bardi, R. Payri, Engine Combustion Network (ECN): Characterization and comparison of boundary conditions for different combustion vessels, Atomization Sprays 22 (9) (2012) $777-806$.

[15] S. Bhattacharjee, D. C. Haworth, Simulations of transient n-heptane and n-dodecane spray flames under engine-relevant conditions using a transported PDF method, Combust. Flame 160 (10) (2013) 2083-2102.

[16] G. D'Errico, T. Lucchini, F. Contino, M. Jangi, X.-S. Bai, Comparison of well-mixed and multiple representative interactive flamelet approaches for diesel spray combustion modelling, Combust. Theor. Model. 18 (1) (2013) 65-88.

[17] P. Kundu, Y. Pei, M. Wang, M. Raju, S. Som, Evaluation of turbulence chemistry interaction under diesel engine conditions with multi-flamelet RIF model, Atomization Sprays 24 (9) (2014) 779-800.

[18] Y. Pei, M. J. Davis, L. M. Pickett, S. Som, Engine Combustion Network (ECN): Global sensitivity analysis of Spray A for different combustion vessels, Combust. Flame 162 (6) (2015) 2337-2347.

[19] C. Gong, M. Jangi, X.-S. Bai, Large eddy simulation of n-dodecane spray combustion in a high pressure combustion vessel, Appl. Energy 136 (2014) 373-381.

[20] Y. Pei, S. Som, E. Pomraning, P. K. Senecal, S. A. Skeen, J. Manin, L. M. Pickett, Large eddy simulation of a reacting spray flame with 
multiple realizations under compression ignition engine conditions, Combust. Flame (2015), doi:10.1016/j.combustflame.2015.08.010.

[21] Y. Pei, P. Kundu, G. M. Goldin, S. Som, Large eddy simulation of a reacting spray flame under diesel engine conditions, SAE paper (2015), 2015-01-1844.

[22] Y. Pei, B. Hu, S. Som, Large eddy simulation of an n-dodecane spray flame under different ambient oxygen conditions, ASME ICEF (2015), 2015-1034.

[23] M. Chishty, Y. Pei, E. Hawkes, M. Bolla, S. Kook, Investigation of the flame structure of Spray-A using the transported probability density function, $19^{\text {th }}$ Australasian Fluid Mechanics Conference, Melbourne, Australia, 8-11 December 2014.

[24] A. Wehrfritz, V. Vuorinen, O. Kaario, M. Larmi, Large eddy simulation of high-velocity fuel sprays: Studying mesh resolution and breakup model effects for Spray A, Atomization Sprays 23 (5) (2013) 419-442.

[25] Q. Xue, S. Som, P. K. Senecal, E. Pomraning, Large eddy simulation of fuel-spray under non-reacting IC engine conditions, Atomization Sprays 23 (10) (2013) 925-955.

[26] Y. Pei, E. R. Hawkes, S. Kook, G. M. Goldin, T. Lu, Modelling ndodecane spray and combustion with the transported probability density function method, Combust. Flame 162 (5) (2015) 2006-2019.

[27] Y. Pei, Transported PDF modelling of spray combustion at practical 
diesel engine conditions, Ph.D. thesis, The University of New South Wales, Sydney, Australia (2013).

[28] R. Barlow, C. Carter, Raman/Rayleigh/LIF measurements of nitric oxide formation in turbulent hydrogen jet flames, Combust. Flame 97 (3) (1994) 261-280.

[29] A. Masri, R. Dibble, R. Barlow, The structure of turbulent nonpremixed flames revealed by Raman-Rayleigh-LIF measurements, Prog. Energy Combust. Sci. 22 (4) (1996) 307-362.

[30] W. Meier, A. Vyrodov, V. Bergmann, W. Stricker, Simultaneous Raman/LIF measurements of major species and $\mathrm{NO}$ in turbulent $\mathrm{H}_{2}$ /air diffusion flames, Appl. Phys. B 63 (1) (1996) 79-90.

[31] W. Meier, R. Barlow, Y.-L. Chen, J.-Y. Chen, Raman/Rayleigh/LIF measurements in a turbulent $\mathrm{CH}_{4} / \mathrm{H}_{2} / \mathrm{N}_{2}$ jet diffusion flame: experimental techniques and turbulence-chemistry interaction, Combust. Flame 123 (3) (2000) 326-343.

[32] R. Barlow, G. Fiechtner, C. Carter, J.-Y. Chen, Experiments on the scalar structure of turbulent $\mathrm{CO} / \mathrm{H}_{2} / \mathrm{N}_{2}$ jet flames, Combust. Flame 120 (4) (2000) 549-569.

[33] D. Geyer, A. Kempf, A. Dreizler, J. Janicka, Scalar dissipation rates in isothermal and reactive turbulent opposed-jets: 1-D-Raman/Rayleigh experiments supported by LES, Proc. Combust. Inst. 30 (1) (2005) 681689. 
[34] J. Hult, U. Meier, W. Meier, A. Harvey, C. Kaminski, Experimental analysis of local flame extinction in a turbulent jet diffusion flame by high repetition 2-D laser techniques and multi-scalar measurements, Proc. Combust. Inst. 30 (1) (2005) 701-709.

[35] A. N. Karpetis, R. S. Barlow, Measurements of flame orientation and scalar dissipation in turbulent partially premixed methane flames, Proc. Combust. Inst. 30 (1) (2005) 665-672.

[36] A. N. Karpetis, T. B. Settersten, R. W. Schefer, R. S. Barlow, Laser imaging system for determination of three-dimensional scalar gradients in turbulent flames, Optics Letters 29 (4) (2004) 355-357.

[37] R. L. Gordon, A. R. Masri, S. B. Pope, G. M. Goldin, A numerical study of auto-ignition in turbulent lifted flames issuing into a vitiated co-flow, Combust. Theor. Model. 11 (3) (2007) 351-376.

[38] R. L. Gordon, A. R. Masri, S. B. Pope, G. M. Goldin, Transport budgets in turbulent lifted flames of methane autoigniting in a vitiated co-flow, Combust. Flame 151 (3) (2007) 495-511.

[39] M. M. Ameen, J. Abraham, RANS and LES study of lift-off physics in reacting diesel jets, SAE paper (2014), 2014-01-1118.

[40] A. Irannejad, A. Banaeizadeh, F. Jaberi, Large eddy simulation of turbulent spray combustion, Combust. Flame 162 (2) (2015) 431-450.

[41] Y. Pei, E. R. Hawkes, S. Kook, A comprehensive study of effects of mixing and chemical kinetic models on predictions of n-heptane jet ignitions with the PDF method, Flow, Turbul. Combust. 91 (2) (2013) 249-280. 
[42] Y. Pei, E. R. Hawkes, S. Kook, Transported probability density function modelling of the vapour phase of an n-heptane jet at diesel engine conditions, Proc. Combust. Inst. 34 (2) (2013) 3039-3047.

[43] ANSYS, FLUENT 14.5 Theory Guide,, Tech. rep., ANSYS Inc., Canonsburg, US (2011).

[44] S. Subramaniam, S. Pope, A mixing model for turbulent reactive flows based on Euclidean minimum spanning trees, Combust. Flame 115 (4) (1998) 487-514.

[45] R. Cao, S. Pope, Numerical integration of stochastic differential equations: weak second-order mid-point scheme for application in the composition PDF method, J. Comput. Phys. 185 (1) (2003) 194-212.

[46] S. Sarathy, C. Westbrook, M. Mehl, W. Pitz, C. Togbe, P. Dagaut, H. Wang, M. Oehlschlaeger, U. Niemann, K. Seshadri, et al., Comprehensive chemical kinetic modeling of the oxidation of 2-methylalkanes from $\mathrm{C}_{7}$ to $\mathrm{C}_{20}$, Combust. Flame 158 (12) (2011) 2338-2357.

[47] Z. Luo, S. Som, S. M. Sarathy, M. Plomer, W. J. Pitz, D. E. Longman, T. Lu, Development and validation of an n-dodecane skeletal mechanism for spray combustion applications, Combust. Theor. Model. 18 (2) (2014) 187-203.

[48] J. M. Hall, E. L. Petersen, An optimized kinetics model for $\mathrm{OH}$ chemiluminescence at high temperatures and atmospheric pressures, Int. J. Chem. Kinet. 38 (12) (2006) 714-724. 
[49] S. Pope, Computationally efficient implementation of combustion chemistry using in situ adaptive tabulation, Combust. Theor. Model. 1 (1997) 41-63.

[50] J. K. Dukowicz, A particle-fluid numerical model for liquid sprays, J. Comput. Phys. 35 (2) (1980) 229-253.

[51] R. Clift, J. Grace, M. Weber, Bubbles, drops and particles, Academic Press, New York, (1978).

[52] A. Gosman, E. Ioannides, Characterization of a set of ECN Spray A injectors: Nozzle to nozzle variations and effect on spray characteristics, J. Energy 7 (6) (1983) 482-490.

[53] N. Frossling, Evaporation, heat transfer, and velocity distribution in two-dimensional and rotationally symmetrical laminar boundary-layer flow, N.A.C.A. 168 (1956) AD-B189.

[54] W. Ranz, W. Marshall, Evaporation from drops, Chem. Eng. Prog. 48 (3) (1952) 141-146.

[55] S. V. Patankar, D. B. Spalding, A calculation procedure for heat, mass and momentum transfer in three-dimensional parabolic flows, Int. J. Heat Mass Transf. 15 (10) (1972) 1787-1806.

[56] C. Rhie, W. Chow, Numerical study of the turbulent flow past an airfoil with trailing edge separation, AIAA 21 (11) (1983) 1525-1532.

[57] J. M. Garcia-Oliver, Mixing and chemistry interactions, ECN3 Proc. (2014) http://www.ca.sandia.gov/ecn/workshop/ECN3.php. 
[58] E. Mastorakos, T. Baritaud, T. Poinsot, Numerical simulations of autoignition in turbulent mixing flows, Combust. Flame 109 (1) (1997) $198-223$.

[59] R. Kee, F. Rupley, J. Miller, M. Coltrin, J. Grcar, E. Meeks, H. Moffat, A. Lutz, G. Dixon-Lewis, M. Smooke, et al., Chemkin collection, release 4.1, Reaction Design Inc., San Diego, CA.

[60] N. Peters, Laminar flamelet concepts in turbulent combustion, Symp. (Int.) Combust. 21 (1) (1988) 1231-1250.

[61] S. Mukhopadhyay, J. Abraham, Influence of compositional stratification on autoignition in n-heptane/air mixtures, Combust. Flame 158 (6) (2011) 1064-1075.

[62] S. Mukhopadhyay, J. Abraham, Influence of turbulence on autoignition in stratified mixtures under compression ignition engine conditions, J. Automob. Eng. 227 (5) (2013) 748-760.

[63] E. Mastorakos, Ignition of turbulent non-premixed flames, Prog. Energy Combust. Sci. 35 (1) (2009) 57-97.

[64] T. Echekki, J. H. Chen, Direct numerical simulation of autoignition in non-homogeneous hydrogen-air mixtures, Combust. Flame 134 (3) (2003) 169-191.

[65] R. Sankaran, H. G. Im, E. R. Hawkes, J. H. Chen, The effects of nonuniform temperature distribution on the ignition of a lean homogeneous hydrogen-air mixture, Proc. Combust. Inst. 30 (1) (2005) 875-882. 
[66] S. Sreedhara, K. Lakshmisha, Autoignition in a non-premixed medium: DNS studies on the effects of three-dimensional turbulence, Proc. Combust. Inst. 29 (2) (2002) 2051-2059.

[67] S. Liu, J. C. Hewson, J. H. Chen, Nonpremixed n-heptane autoignition in unsteady counterflow, Combust. Flame 145 (4) (2006) 730-739.

[68] C. K. Westbrook, J. Warnatz, W. J. Pitz, A detailed chemical kinetic reaction mechanism for the oxidation of iso-octane and n-heptane over an extended temperature range and its application to analysis of engine knock, Symp. (Int.) Combust. 22 (1) (1989) 893-901.

[69] L. Pickett, S. Kook, T. Williams, Visualization of diesel spray penetration, cool-flame, ignition, high-temperature combustion, and soot formation using high-speed imaging, SAE Int. J. Engines 2 (1) (2009) 439-459.

[70] S. Kook, L. Pickett, Effect of fuel volatility and ignition quality on combustion and soot formation at fixed premixing conditions, SAE Int. J. Engines 2 (2) (2010) 11-23.

[71] S. Skeen, J. Manin, L. M. Pickett, Visualization of ignition processes in high-pressure sprays with multiple injections of n-dodecane, SAE Int. J. Engines 8 (2) (2015) 696-715.

[72] L.-M. Malbec, G. D'Errico, Mixing and velocity session, ECN2 Proc. (2012) http://www.ca.sandia.gov/ecn/workshop/ECN2.php. 
[73] L. M. Pickett, S. Kook, H. Persson, Ö. Andersson, Diesel fuel jet liftoff stabilization in the presence of laser-induced plasma ignition, Proc. Combust. Inst. 32 (2) (2009) 2793-2800.

[74] R. Venugopal, J. Abraham, A review of fundamental studies relevant to flame lift-off in diesel jets, SAE paper (2007), 2007-01-0134.

[75] A. Krisman, E. R. Hawkes, M. Talei, A. Bhagatwala, J. H. Chen, Polybrachial structures in dimethyl ether edge-flames at negative temperature coefficient conditions, Proc. Combust. Inst. 35 (1) (2015) 999-1006.

[76] S. Karami, E. R. Hawkes, M. Talei, J. H. Chen, Mechanisms of flame stabilisation at low lifted height in a turbulent lifted slot-jet flame, J. Fluid Mech. 777 (2015) 633-689.

[77] Y. Zel'dovich, Regime classification of an exothermic reaction with nonuniform initial conditions, Combust. Flame 39 (1980) 211-214.

[78] J. H. Chen, E. R. Hawkes, R. Sankaran, S. D. Mason, H. G. Im, Direct numerical simulation of ignition front propagation in a constant volume with temperature inhomogeneities: I. fundamental analysis and diagnostics, Combust. Flame 145 (1) (2006) 128-144.

[79] E. R. Hawkes, R. Sankaran, P. P. Pébay, J. H. Chen, Direct numerical simulation of ignition front propagation in a constant volume with temperature inhomogeneities: II. parametric study, Combust. Flame 145 (1) (2006) 145-159.

[80] M. Jangi, X. Zhao, D. C. Haworth, X.-S. Bai, Stabilization and liftoff 
length of a non-premixed methane/air jet flame discharging into a hightemperature environment: An accelerated transported PDF method, Combust. Flame 162 (2) (2015) 408-419.

[81] H. Yamashita, M. Shimada, T. Takeno, A numerical study on flame stability at the transition point of jet diffusion flames, Symp. (Int.) Combust. 26 (1) (1996) 27-34.

[82] C. Yoo, R. Sankaran, J. Chen, Three-dimensional direct numerical simulation of a turbulent lifted hydrogen jet flame in heated coflow: flame stabilization and structure, J. Fluid Mech. 640 (2009) 453-481.

[83] P. Domingo, L. Vervisch, J. Réveillon, DNS analysis of partially premixed combustion in spray and gaseous turbulent flame-bases stabilized in hot air, Combust. Flame 140 (3) (2005) 172-195.

[84] Y. Mizobuchi, S. Tachibana, J. Shinio, S. Ogawa, T. Takeno, A numerical analysis of the structure of a turbulent hydrogen jet lifted flame, Proc. Combust. Inst. 29 (2) (2002) 2009-2015.

[85] C. K. Westbrook, W. J. Pitz, O. Herbinet, H. J. Curran, E. J. Silke, A comprehensive detailed chemical kinetic reaction mechanism for combustion of n-alkane hydrocarbons from n-octane to n-hexadecane, Combust. Flame 156 (1) (2009) 181-199.

[86] R. Barlow, J. Frank, Effects of turbulence on species mass fractions in methane/air jet flames, Symp. (Int.) Combust. 27 (1) (1998) 1087-1095.

[87] N. Peters, Turbulent combustion, Cambridge University Press, 2000. 
[88] E. R. Hawkes, O. Chatakonda, H. Kolla, A. R. Kerstein, J. H. Chen, A petascale direct numerical simulation study of the modelling of flame wrinkling for large-eddy simulations in intense turbulence, Combust. Flame 159 (8) (2012) 2690-2703.

[89] O. Chatakonda, E. R. Hawkes, A. J. Aspden, A. R. Kerstein, H. Kolla, J. H. Chen, On the fractal characteristics of low Damköhler number flames, Combust. Flame 160 (11) (2013) 2422-2433.

[90] W. K. Bushe, H. Steiner, Conditional moment closure for large eddy simulation of nonpremixed turbulent reacting flows, Phys. Fluids (1994present) 11 (7) (1999) 1896-1906.

[91] R. Grout, W. K. Bushe, C. Blair, Predicting the ignition delay of turbulent methane jets using conditional source-term estimation, Combust. Theor. Model. 11 (6) (2007) 1009-1028.

[92] W. K. Bushe, H. Steiner, Laminar flamelet decomposition for conditional source-term estimation, Phys. Fluids (1994-present) 15 (6) (2003) 15641575 .

[93] C. Bekdemir, L. Somers, L. de Goey, Modeling diesel engine combustion using pressure dependent flamelet generated manifolds, Proc. Combust. Inst. 33 (2) (2011) 2887-2894.

[94] C. Bajaj, M. Ameen, J. Abraham, Evaluation of an unsteady flamelet progress variable model for autoignition and flame lift-off in diesel jets, Combust. Sci. Tech. 185 (3) (2013) 454-472. 
[95] Y. Yang, S. B. Pope, J. H. Chen, Empirical low-dimensional manifolds in composition space, Combust. Flame 160 (10) (2013) 1967-1980.

[96] I. Jolliffe, Principal component analysis, Wiley Online Library, 2002.

[97] J. H. Friedman, Multivariate adaptive regression splines, Ann. Stat. (1991) 1-67. 